\title{
Changing travel behaviour and attitudes following a residential relocation
}

\author{
Jonas De Vos, Dick Ettema, Frank Witlox
}

\begin{abstract}
A considerable amount of studies have indicated that people to some extent select themselves in specific neighbourhoods allowing them to travel in their desired way. Although a lot of studies analysed the degree to which travel preferences affect the residential location choice, few studies looked at the effect of a residential relocation on people's travel behaviour and attitudes. A new residential context has the potential to disrupt previous travel choices and could potentially change people's attitudes. This study - using 1,539 recently relocated residents in the city of Ghent (Belgium) - analyses self-reported changes in mode frequency and travel attitudes after a relocation, and uses a cohort approach to look at mode frequency and attitudes at different times after the relocation took place. Results suggest that (i) travel attitudes often influence the residential location choice, and (ii) both travel attitudes and travel mode choice change after a relocation, albeit in different ways depending on the current (urban versus suburban) and previous residential neighbourhood (more/equally/less urbanised). This study also suggests that a (possible) dissonance between travel attitudes and the residential neighbourhood is partly a temporal situation, as attitudes can gradually change in accordance with the new residential environment.
\end{abstract}

Keywords: Travel behaviour; Travel attitudes; Residential relocation; Residential self-selection

\section{Introduction}

Numerous studies have indicated that the residential neighbourhood has an important impact on people's travel behaviour. People living in compact, mixed-use areas with good public transport services often walk, cycle or use public transport, while people living in low-density, single-use environments with limited access to public transport use the car for most of their trips (e.g., Cervero \& Kockelman, 1997; De Vos \& Witlox, 2013; Ewing \& Cervero, 2001, 2010). As a result, motivating people to live in urban areas is often put forward as a way to discourage car use. A residential relocation, which can be seen as an important life event, can create a new context - with new travel options and travel restrictions - in which certain travel choices are likely to be (re)considered (Bamberg, 2006; Klinger \& Lanzendorf, 2016; Scheiner, 2006; Verplanken et al., 2008). In other words, a relocation to compact, mixed-use areas has the potential to unfreeze undesired travel habits, such as repetitive car use, and stimulate active travel and public transport use. However, travel behaviour is also affected by attitudes (e.g., Bagley \& Mokhtarian, 2002; Handy et al., 2005; Kitamura et al., 1997; Van Acker et al., 2011), which might not directly change after a relocation takes place. The extent to which the residential location choice is based on travel preferences might also influence changes in travel behaviour after a relocation. If people select themselves in certain neighbourhoods based on their travel preferences, it is likely that they will use travel modes stimulated by the new neighbourhood (i.e., car use in suburban neighbourhoods; public transport and active travel in urban neighbourhoods) (De Vos et al., 2012; Schwanen \& Mokhtarian, 2005). In case the residential location choice is based on other elements - which are not related with travel (affordability, housing characteristics, etc.) - it is possible that a modal shift will not occur easily as the residents' travel 
attitudes might not match with the travel behaviour stimulated by the new neighbourhood (De Vos et al., 2014; Kamruzzaman et al., 2013). On the other hand, it is also possible that people change their travel attitudes based on their new residential environment and accompanying travel patterns (Lin et al., 2017; Næss, 2009; Wang \& Lin, 2018). Up till now, it remains rather unclear how travel attitudes and travel mode choices evolve after a residential relocation has taken place.

In this study we will look at changing attitudes and mode frequency of people who recently relocated within the city of Ghent, Belgium. A subdivision is made based on the current residential neighbourhood (urban versus suburban) and the previous residential neighbourhood (less/equally urbanised versus equally/more urbanised) resulting in four groups of respondents. To the best of our knowledge, this quasi-longitudinal and partly retrospective study is the first study with a large sample size (1,500+ respondents) and high level of detail looking at changes in both attitudes and mode choice after a residential relocation takes place. This paper is organised as follows. Section 2 reviews literature on (i) the effect of travel attitudes on the residential location choice, and (ii) the (potential) effect of a residential relocation on travel behaviour and attitudes. The data and methods used are presented in Section 3, while Section 4 shows the major results. Discussion and conclusions are provided in Section 5.

\section{Travel and residential location}

\subsection{Effect of travel preferences on the residential location choice}

Although many studies have found significant differences in travel mode choice between people living in urban and suburban neighbourhoods, the effect of the built environment on travel behaviour might be indirect, through travel attitudes and preferences. Studies have indicated that people tend to select themselves in neighbourhoods facilitating the use of their preferred travel mode (e.g., De Vos et al., 2012; Handy et al., 2005; Schwanen \& Mokhtarian, 2005), suggesting that attitudes explain travel mode choice to a larger extent than the built environment. However, nearly all studies on residential self-selection also found evidence of statistically significant associations between the built environment and travel behaviour, independent of self-selection influences (Cao et al., 2009a; Næss, 2014; Ewing and Cervero, 2010).

The concept of residential self-selection implies that people's residential location choice is based on travel preferences and attitudes. People will try to select themselves in neighbourhoods enabling them to travel in their desired way. People preferring to travel by car might be more inclined to live in suburban style neighbourhoods, due to good car accessibility, limited parking problems, etc. People who like active travel or public transport use might prefer to live in a more urban-type neighbourhood. Due to high density and land use mixing, destinations are often within walking or cycling distance, while public transport is available and mostly well-organised in urban areas. Besides mode-specific attitudes, it is also possible that travel-liking attitudes influence the residential location choice. De Vos and Witlox (2016), for instance, suggest that people who do not like to travel select themselves in urban neighbourhoods in order to limit travel distance and travel time. According to Cao and Ettema (2014), people will try to choose a neighbourhood enabling them to have more satisfying trips.

However, the concept of residential self-selection has frequently been questioned. Recently, Wang and Lin (2018) - analysing travel behaviour and attitudes before and after a residential relocation in 
Beijing - found no significant effects of pre-move travel preferences on post-move built environment, suggesting that the role of travel attitudes on the residential location choice is limited or at least not uniform across different geographical contexts. Other studies found that travel-related preferences often do not match with the chosen residential neighbourhood. Based on attitudes towards living in a high-density neighbourhood (Schwanen \& Mokhtarian, 2004, 2005), travelling with alternatives for the car (De Vos et al., 2012), travelling with public transport (Kamruzzaman et al., 2013), travel in general (De Vos \& Witlox, 2016), and a combination of travel and residential preferences (De Vos et al., 2016), it has been found that the residential neighbourhood does not match with attitudes for 23.6\% (Schwanen \& Mokhtarian, 2004) to 51.4\% (De Vos et al., 2012) of the neighbourhoods' residents. Such a dissonance between travel/residential preferences and the chosen neighbourhood - referred to as residential dissonance - can mainly be explained by the fact that the residential location choice is influenced by a wide range of elements and that the choice of where to live is often based on reasons other than transport, such as characteristics of the dwelling and neighbourhood (e.g., Chatman, 2009; Ettema and Nieuwenhuis, 2017, Wolday et al., 2018). Furthermore, elements such as distance to work, varying preferences within households and budget limitations can constrain people's residential location choice. Lin et al. (2017) divide individuals into two groups based on whether they have the freedom to choose a neighbourhood based on travel attitudes/preferences, or not. The first situation is referred to as residential self-selection, while the latter is called residential determination. Due to a limited freedom of where to live, residential determination can result in a chosen neighbourhood which is not the preferred one (i.e., residential dissonance).

\subsection{Potential effects of a residential relocation on travel behaviour and attitudes}

Although many studies have looked at the role of travel preferences on the residential location choice, only a few studies have looked at how travel behaviour and attitudes change after a residential relocation. This might be explained by the fact that it is sometimes difficult to get information of people who recently relocated, partly due to privacy regulations. It is even more difficult to get information of respondents before and after a relocation as it is almost impossible to know when people will relocate. The limited amount of studies found that people relocating to urban-type neighbourhoods or Transit-Oriented Developments (TODs) walk, cycle and use public transport more often and travel less by car than in their previous neighbourhood (Aditjandra et al., 2016; Cao \& Ermagun, 2017; Giles-Corti et al., 2013; Krizek, 2003; Scheiner \& Holz-Rau, 2013; Woods \& Ferguson, 2014), while opposite results can be found for people relocating to more suburban-type neighbourhoods (Scheiner \& Holz-Rau, 2013). These results can be partly explained by changes in household car possession (Aditjandra et al., 2016; Scheiner \& Holz-Rau, 2013; Woods \& Ferguson, 2014). Some studies found that people often change their travel mode after a relocation, independent from the type of previous and new neighbourhood (Fatmi \& Habib, 2017; Klinger \& Lanzendorf, 2016; Scheiner, 2006), while Wang and Lin (2018) found that people mostly maintain their travel behaviour after residential relocation.

Although some studies have suggested that the built environment can impact people's travel attitudes, whether or not through travel patterns stimulated by the new built environment (Cao et al., 2009b; Chatman, 2009; Handy et al., 2005; Kamruzzaman et al., 2016; Kitamura et al., 1997; Lin et al., 2017; Næss, 2009, 2014), only a few have actually tested it. Bagley and Mokhtarian (2002) - using cross-sectional data of residents in the San Francisco Bay Area - found no significant effects of 
respondents' residential location on attitudes towards travel and housing preferences, while van de Coevering et al. (2016) - using longitudinal data of Dutch residents - found that living far away from a railway station positively affects attitudes towards car use while negatively affecting attitudes towards public transport use. Only one study has analysed travel attitudes before and after a residential relocation took place. Wang and Lin (2018) - using panel data from Beijing (China) - found that preferences towards travel modes significantly changed after respondents moved. ${ }^{1}$ The influence of the built environment on travel-related attitudes is referred to as the 'reverse causality' hypothesis by van de Coevering et al. (2016). According to them, such a reverse causality can occur when people adjust their attitudes to their preceding residential location choice or when they start valuing the travel modes stimulated by the neighbourhoods' built environment.

In this study we assume that both attitudes and mode choice can and will change after a residential relocation. However, these changes might differ according to whether the residential location choice is based on travel preferences, and whether the new residential environment differs from the previous residential environment in terms of physical characteristics such as density, diversity and design. In case of residential self-selection, the residential location choice is highly affected by travel-related attitudes. When people move to a similar type of neighbourhood, it can be expected that attitudes and mode choice stay congruent with the chosen neighbourhood, i.e., pro car attitudes and high share of car use in suburban-type neighbourhoods, and pro public transport/active travel and low share of car use in urban neighbourhoods. When people move to a different type of neighbourhood, but still based on travel attitudes, it can be expected that mode choice, affected by both attitudes and the built environment (abbreviated as $\mathrm{BE}$ ), will change consistent with the new residential location (Figure 1).

In case of residential determination, the residential location choice is not based on travel preferences, but on a wide range of elements (income levels, distance to work, etc.). Therefore, it can be expected that people's attitudes are - when relocating - not in line with the new residential environment, and a residential dissonance occurs. However, it can be assumed that people will change their attitudes according to the new environment (Lin et al., 2017; Næss, 2009; Wang \& Lin, 2018). Changes in mode choice after the relocation will partly depend on the previous place of residence. People moving from a similar type of neighbourhood will probably already travel frequently with the travel mode(s) stimulated by the residential environment, while people who move to a different type of neighbourhood will probably see a considerable mode shift, due to the new built environment and changing attitudes (Figure 2).

\footnotetext{
${ }^{1}$ It should be noted that Bamberg (2006) also found changing attitudes towards travel (i.e., improved attitudes towards public transport use) of respondents who recently relocated to Stuttgart (Germany). However, this was in combination with providing respondents free public transport passes and detailed public transport service information.
} 

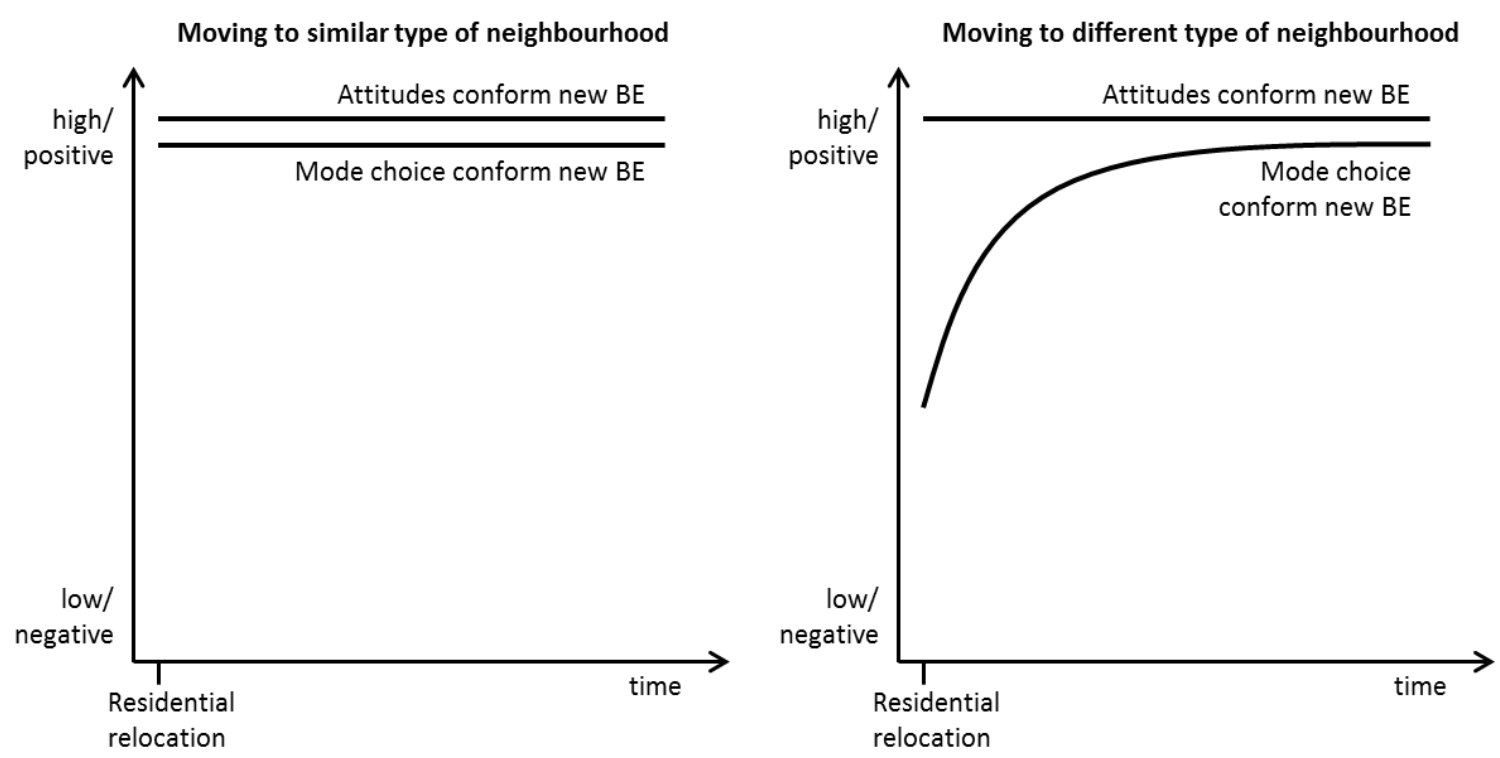

Figure 1. Hypothesised evolution of attitudes and mode choice after a residential relocation in case residential location choice is based on travel preferences (i.e., residential self-selection).
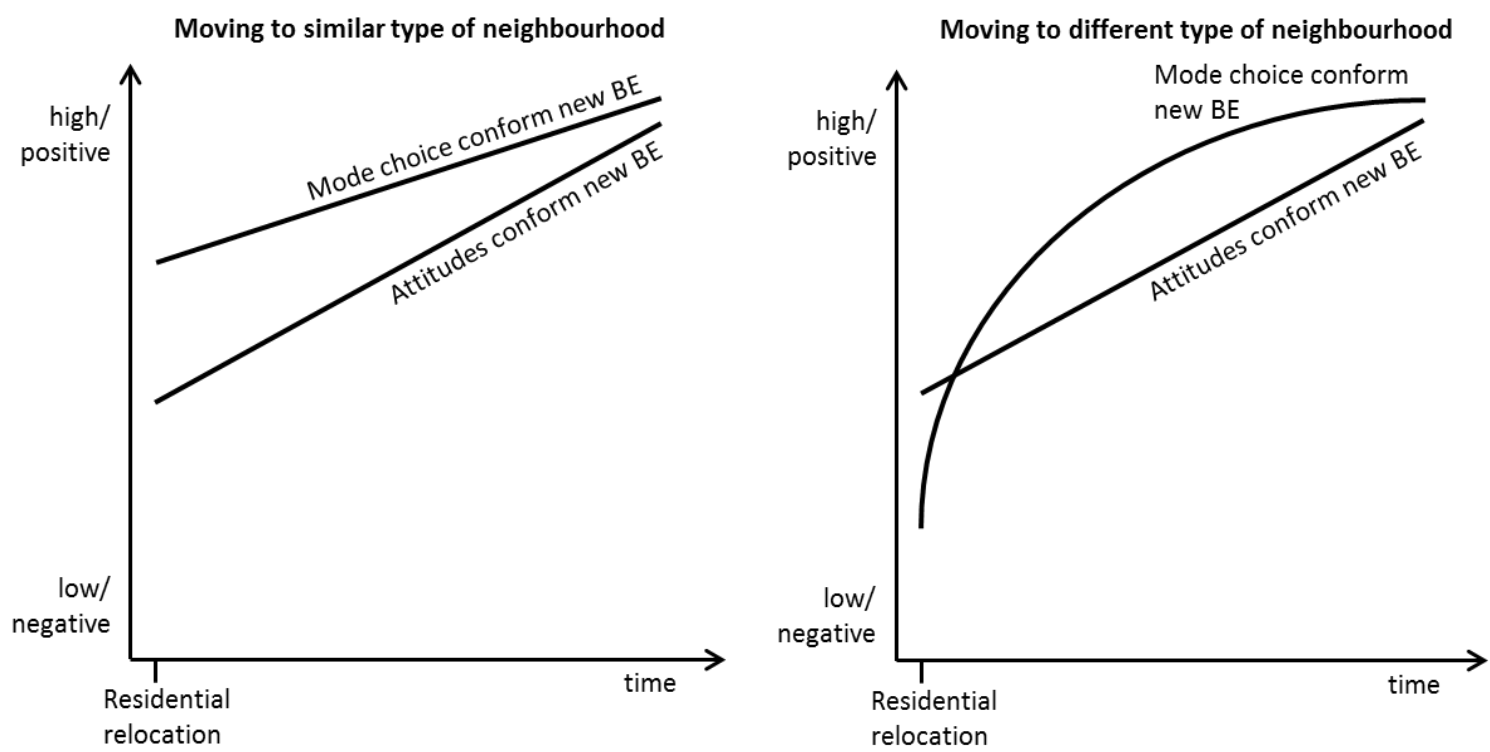

Figure 2. Hypothesised evolution of attitudes and mode choice after a residential relocation in case residential location choice is not based on travel preferences (i.e., residential determination).

In Figures 1 and 2, we assume that travel-related attitudes change over time. Since previous studies have indicated that travel attitudes and mode choice are mostly consistent with the residential neighbourhood people live in (e.g., Handy et al., 2005; Schwanen \& Mokhtarian, 2005; van Wee, 2009), this indicates that after a certain amount of time both attitudes and mode choice will evolve in this direction. As a result, the extent of a possible dissonance between the residential neighbourhood and travel attitudes will probably reduce over time. In this study we will test the hypotheses presented in Figures 1 and 2. 


\section{Data}

\subsection{Neighborhood selection}

For this study we use a 2017 Internet survey on travel behaviour of recently relocated people within the city of Ghent, Belgium (258,000 inhabitants). After screening all neighbourhoods within the city, two internally homogeneous sets of urban and suburban residential neighbourhoods were selected (Figure 3). The group of urban neighbourhoods - located directly around the central business area and all built before the Second World War - are characterised by a relatively high average density (i.e., 8,033 inhabitants per $\mathrm{km}^{2}$ ), highly mixed land uses and can be regarded as a low-traffic area with good public transport services. In general, the street network is characterised by small building blocks, high intersection density, $\mathrm{X}$-intersections and a lack of cul-de-sacs. As a result, street connectivity is high, stimulating active travel (e.g., Ewing \& Cervero, 2010; Saelens et al., 2003; Sallis et al., 2004). The suburban neighbourhoods are located at the edge of the city of Ghent, approximately 3 to 6 kilometres from the city centre. These neighbourhoods - for most parts built after the Second World War - have a considerably lower average density (i.e., 1,819 inhabitants per $\mathrm{km}^{2}$ ), lower diversity, and limited public transport services. The street network is characterised by relatively large building blocks, low intersection density, and a high number of T-intersections and cul-de-sacs. The resulting low levels of connectivity stimulate car use and discourage active travel. Approximately 101,300 people (situation 2016) reside in the selected neighbourhoods, accounting for $39.3 \%$ of all residents in the city of Ghent (Table 1). 


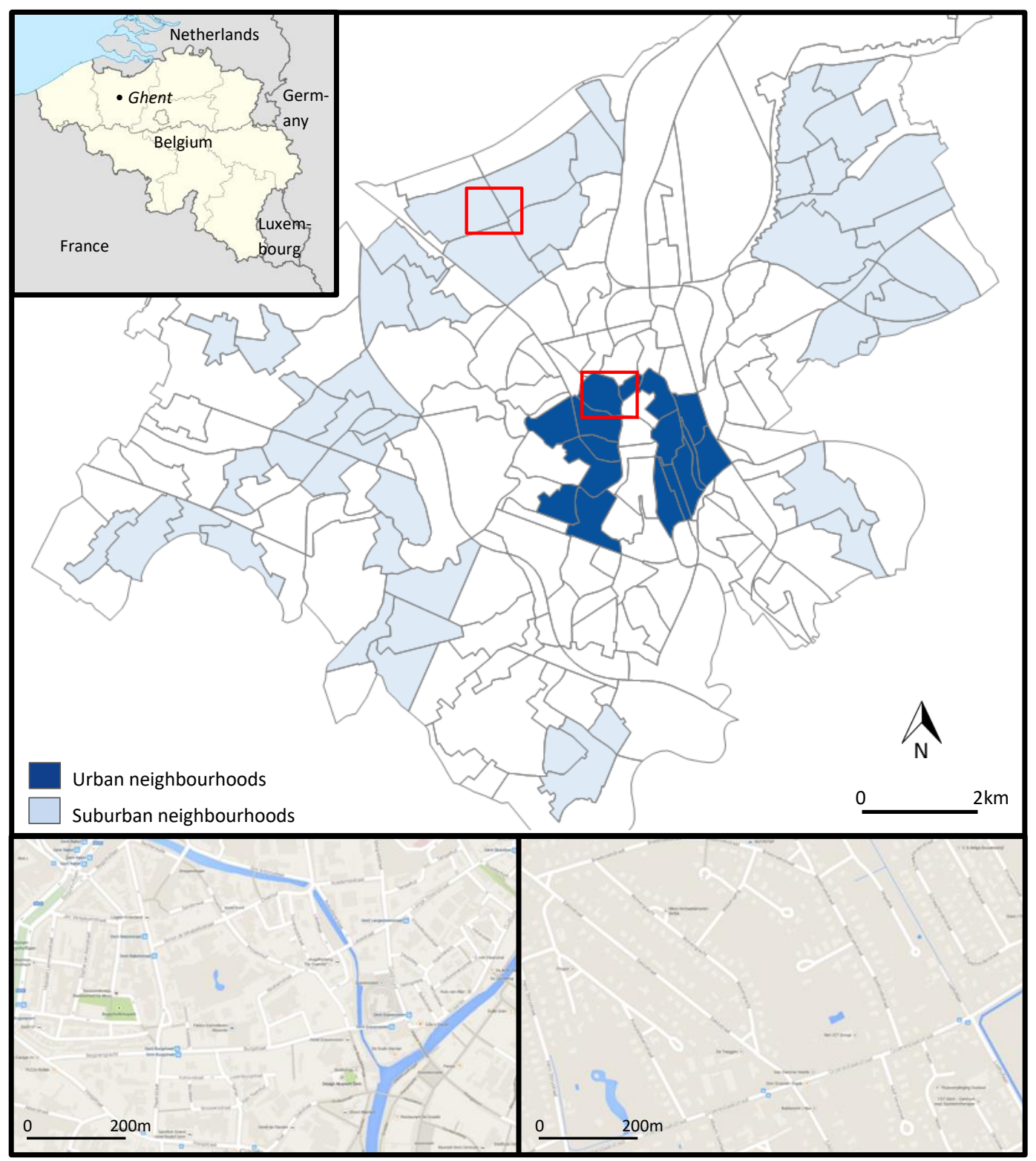

Figure 3. Distribution of urban and suburban neighbourhoods within the city of Ghent. The location of the street networks (bottom left: urban neighbourhood; bottom right: suburban neighbourhood) are indicated by red boxes on the map above.

In socio-demographic terms, considerable differences can be found between residents from urban and suburban neighbourhoods (Table 1). In comparison with urban neighbourhoods, suburban neighbourhoods are characterised by larger household sizes. Couples, often with children tend to live in suburban neighbourhoods, while more than half of the residents in urban areas are singles. As a result, the group of people younger than 20 years old can mainly be found in suburban neighbourhoods. People aged between 20 and 39 are well represented in urban neighbourhoods, while people older than 40 tend to live more frequently in suburban neighbourhoods. The urban neighbourhoods are - compared to suburban neighbourhoods - characterised by lower median incomes, a higher share of citizens from outside the EU-15 area, a higher unemployment rate and more rental homes. Urban dwellings are also smaller and older than suburban dwellings. 
Table 1. Neighbourhood characteristics (in 2016) (http://gent.buurtmonitor.be)

\begin{tabular}{|c|c|c|}
\hline & $\begin{array}{c}\text { Urban } \\
\text { neighbourhoods }\end{array}$ & $\begin{array}{c}\text { Suburban } \\
\text { neighbourhoods }\end{array}$ \\
\hline \multicolumn{3}{|l|}{ Physical characteristics } \\
\hline \multicolumn{3}{|l|}{ Density indicators } \\
\hline Population & 39,682 & 61,625 \\
\hline Area $\left(\mathrm{km}^{2}\right)$ & 4.94 & 33.88 \\
\hline Population density (population $/ \mathrm{km}^{2}$ ) & 8,033 & 1,819 \\
\hline Building density (\%) & 38.8 & 12.6 \\
\hline \multicolumn{3}{|l|}{ Diversity indicators } \\
\hline Number of bars/restaurants/hotels & 410 & 119 \\
\hline (per km²/per 1,000 inhabitants) & $(83.00 / 10.33)$ & $(3.51 / 1.93)$ \\
\hline Number of services ${ }^{a}$ & 271 & 190 \\
\hline (per km²/per 1,000 inhabitants) & $(54.86 / 6.83)$ & $(5.61 / 3.10)$ \\
\hline Number of shops for daily goods ${ }^{b}$ & 214 & 133 \\
\hline (per km²/per 1,000 inhabitants) & $(43.32 / 5.83)$ & $(3.93 / 2.16)$ \\
\hline Number of shops for non-daily goods ${ }^{c}$ & 257 & 149 \\
\hline (per $\mathrm{km}^{2} /$ per 1,000 inhabitants) & $(52.02 / 6.49)$ & $(4.40 / 2.42)$ \\
\hline Number of elementary schools & 20 & 28 \\
\hline (per km²/per 1,000 inhabitants) & $(4.05 / 0.50)$ & $(0.83 / 0.45)$ \\
\hline Number of secondary schools & 31 & 9 \\
\hline (per km²/per 1,000 inhabitants) & $(6.28 / 0.78)$ & $(0.27 / 0.15)$ \\
\hline \multicolumn{3}{|l|}{ Dwelling indicators } \\
\hline Average living space per dwelling $\left(\mathrm{m}^{2}\right)$ & 113 & 161 \\
\hline Dwellings older than 1930 (\%) & 81.9 & 15.4 \\
\hline Rental homes (\%) & 65.0 & 29.5 \\
\hline \multicolumn{3}{|l|}{ Population characteristics } \\
\hline \multicolumn{3}{|l|}{ Age distribution } \\
\hline 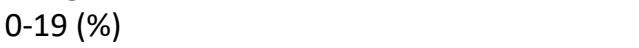 & 13.8 & 21.4 \\
\hline 20-39 (\%) & 44.4 & 22.4 \\
\hline $40-59(\%)$ & 22.4 & 28.0 \\
\hline $60+(\%)$ & 19.5 & 28.2 \\
\hline \multicolumn{3}{|l|}{ Gender } \\
\hline Women/men (\%) & $48.9 / 51.1$ & $51.8 / 48.2$ \\
\hline \multicolumn{3}{|l|}{ Ethnicity } \\
\hline Non-EU (15) citizen (\%) & 11.3 & 2.9 \\
\hline \multicolumn{3}{|l|}{ Income } \\
\hline Median net income/year (euro) & 18,943 & 21,641 \\
\hline \multicolumn{3}{|l|}{ Employment level } \\
\hline Unemployment rate between age $18-65$ (\%) & 9.8 & 4.4 \\
\hline \multicolumn{3}{|l|}{ Household composition } \\
\hline Single (\%) & 57.3 & 28.1 \\
\hline Single parent $(\%)$ & 5.3 & 7.3 \\
\hline Couple without children (\%) & 12.3 & 31.0 \\
\hline Couple with children (\%) & 25.1 & 33.5 \\
\hline \multicolumn{3}{|l|}{ Household size } \\
\hline Average number of household members & 1.74 & 2.41 \\
\hline
\end{tabular}

a Services: banking centers, insurance offices, real estate offices, post offices, hairdressers, travel agencies, beauty salons, employment agencies, etc.;

b Shops for daily goods: grocery stores, supermarkets, night shops, bakeries, butcher's shops, pharmacies, etc.;

c Shops for non-daily goods: furniture shops, clothes shops, shoe shops, toy shops, do-it-yourself (DIY) shops, electronics retailers, jewellers, bicycle shops, car service stations, etc. 


\subsection{Sample recruitment}

Addresses of inhabitants relocating to the set of selected urban and suburban neighbourhoods between January 2015 and December 2016 were obtained from the city of Ghent administration. Since residential mobility turns out to be a lot higher in urban neighbourhoods than in suburban neighbourhoods, we selected a high share of suburban neighbourhoods (i.e., 51 statistical sectors in suburban neighbourhoods versus 16 statistical sectors in urban neighbourhoods), resulting in a considerably larger number of residents in suburban neighbourhoods than in urban neighbourhoods (see Table 1). Although we selected a high number of suburban neighbourhoods, the number of households relocating between January 2015 and December 2016 to these suburban neighbourhoods (i.e., 3,588) is a lot lower than the number of households relocating to the selected urban neighbourhoods (i.e., 6,391). Keeping into account the total number of residents in the selected neighbourhoods, this indicates that residential mobility (frequency of residential change) is 2.77 times (i.e., $\left.(6,391 / 3,588)^{*}(61,625 / 39,682)\right)$ higher in urban neighbourhoods than in suburban neighbourhoods. In February 2017, 9,979 letters with an invitation to participate in this survey were distributed to relocated households in these neighbourhoods $(6,391$ to urban households, 3,588 to suburban households). In the end, 1,650 respondents completed the survey, resulting in a response rate of $16.5 \%$. It has to be noted that this is relatively large sample, considerably larger than other travel behaviour studies focussing on recently relocated residents (Aditjandra et al., 2015; Cao \& Ermagun, 2017; Ettema \& Nieuwenhuis, 2017; Fatmi \& Habib, 2017; Klinger \& Lanzendorf, 2016; Krizek, 2003; Scheiner \& Holz-Rau, 2013; Wang \& Lin, 2018; Woods \& Ferguson, 2014). For this study we use 1,539 respondents as we removed respondents indicating that they already lived at their current dwelling before January $2015 .^{2}$

Table 2 shows socio-demographic differences between urban and suburban respondents. Young adults, singles and relatively low income households are well represented in urban neighbourhoods, while respondents older than 30 , households with children and relatively higher incomes can mainly be found in suburban neighbourhoods. The main difference between our sample and the total population is that older adults $(45+)$ are poorly represented in our sample. However, this is not very surprising as young people are more likely to relocate, related to life events such as leaving the parental home, going to university, entry into the labour market, formation of a household with partner and having children. ${ }^{3}$ It is rather logical that our sample differs to a certain extent from the total population as we selected a subsample of this population (i.e., recently relocated residents). Although we do not have socio-demographic information on all people moving to the selected neighbourhoods - and we can therefore not know whether our sample is representative for all movers - we do have a relatively large sample size, allowing us to estimate relationships among multiple variables with ample confidence (Groves, 1989). Due to applying an online survey it is likely that certain population groups, such as people with a migration background, are underrepresented in our sample. However, since we do not have background information on all movers, it is impossible to know which groups are over- or under-represented.

\footnotetext{
2 These respondents probably registered their relocation officially a certain period of time after they actually relocated.

${ }^{3}$ This is probably also the reason why residential mobility is considerably higher in urban neighbourhoods where young adults are well represented - than in suburban neighbourhoods.
} 
Table 2. Respondents' socio-demographic characteristics

\begin{tabular}{|c|c|c|c|}
\hline & $\begin{array}{c}\text { Urban } \\
\text { respondents }\end{array}$ & $\begin{array}{c}\text { Suburban } \\
\text { respondents }\end{array}$ & Total \\
\hline & $\%$ & $\%$ & $\%$ \\
\hline \multicolumn{4}{|l|}{ Personal characteristics } \\
\hline \multicolumn{4}{|l|}{ Age distribution } \\
\hline $18-29$ & 59.5 & 29.5 & 49.4 \\
\hline $30-44$ & 21.9 & 43.2 & 29.1 \\
\hline $45-59$ & 11.5 & 17.7 & 13.6 \\
\hline $60+$ & 7.1 & 9.6 & 7.9 \\
\hline \multicolumn{4}{|l|}{ Gender } \\
\hline Female & 47.4 & 46.6 & 47.1 \\
\hline \multicolumn{4}{|l|}{ Education } \\
\hline High education (University (college) degree) & 82.3 & 66.7 & 77.0 \\
\hline \multicolumn{4}{|l|}{ Job status } \\
\hline Full time & 73.6 & 72.6 & 73.3 \\
\hline Part time & 10.0 & 11.3 & 10.5 \\
\hline Unemployed & 6.1 & 8.8 & 7.0 \\
\hline Student & 6.9 & 4.8 & 6.2 \\
\hline Retired & 3.4 & 2.5 & 3.1 \\
\hline \multicolumn{4}{|l|}{ Household characteristics } \\
\hline \multicolumn{4}{|l|}{ Household composition } \\
\hline Single & 34.9 & 20.3 & 30.0 \\
\hline Single parent & 4.8 & 8.4 & 6.0 \\
\hline Couple without children & 39.2 & 33.5 & 37.3 \\
\hline Couple with children & 7.1 & 29.9 & 14.8 \\
\hline Other (e.g., living with parents, with friends) & 14.0 & 7.9 & 11.9 \\
\hline \multicolumn{4}{|l|}{ Household net income/month } \\
\hline Low income $(<2000$ euro) & 43.1 & 28.5 & 38.1 \\
\hline Medium income (2000 - 3,499 euro) & 33.9 & 35.9 & 34.6 \\
\hline High income (3500+ euro) & 23.0 & 35.6 & 27.3 \\
\hline \multicolumn{4}{|l|}{ Household car ownership } \\
\hline 0 & 33.5 & 9.4 & 25.3 \\
\hline 1 & 53.7 & 55.6 & 54.3 \\
\hline$>1$ & 12.8 & 35.0 & 20.3 \\
\hline $\mathrm{N}$ & 1,017 & 522 & 1,539 \\
\hline$\%$ & 66.1 & 33.9 & 100 \\
\hline
\end{tabular}

\subsection{Key variables}

\subsubsection{Current and previous residential location}

About one third (i.e., 522 respondents; 33.9\%) of our respondents lives in a suburban neighbourhood, while most respondents (i.e., 1,017 respondents; 66.1\%) live in urban neighbourhoods. We also asked information concerning respondents' previous residential location. Respondents were asked to indicate to what extent their current neighbourhood is less or more urbanised than their previous neighbourhood, going from 1 (far less urbanised) to 5 (far more urbanised). ${ }^{4}$ Based on information on

\footnotetext{
${ }^{4}$ Since we measured the change in the level of urbanisation between the current and previous residential neighbourhood based on a self-report scale, it is possible that respondents interpret urbanisation differently from each other and different from our view on urbanisation. In order to minimize these potential undesired effects, we added the following clarification in the survey at the place of this question: In this study, the level of urbanisation is interpreted as the extent to which an environment is characterised by a high density of buildings and a high diversity of amenities such as shops, dwellings, hotel and catering, offices and schools.
} 
the current and previous residential neighbourhood of respondents, we created four groups of respondents:

- Suburban residents relocated from a suburban-style neighbourhood ( $n=262)$ current neighbourhood is equally or more urbanised than the previous neighbourhood (scores 3 to 5 )

- Suburban residents relocated from a more urbanised neighbourhood $(n=260)$ current neighbourhood is less urbanised than the previous neighbourhood (scores 1 and 2)

- Urban residents relocated from a less urbanised neighbourhood $(n=589)$ current neighbourhood is more urbanised than the previous neighbourhood (scores 4 and 5 )

- Urban residents relocated from an urban-style neighbourhood $(n=428)$ current neighbourhood is equally or less urbanised than the previous neighbourhood (scores 1 to 3 )

\subsubsection{Duration of residence in the new neighbourhood}

In order to get an indication of an evolution in travel attitudes and the use of certain travel modes after a relocation, we subdivided the respondents in three groups of similar size, according to how long before filling out the survey they relocated:

- $\quad$ Respondents who relocated within eight months before filling out the survey (i.e., from May 2016 until December 2016) $(n=496)$

- $\quad$ Respondents who relocated between nine and sixteen months before filling out the survey (i.e., from September 2015 until April 2016) $(n=461)$

- Respondents who relocated more than sixteen months before filling out the survey (i.e., from January 2015 until August 2015) ( $n=582)$

\subsubsection{Travel mode choice}

In this study we focus on respondents' travel mode choice for trips to work or school (in case of higher education students). Respondents were asked to indicate how often - going from never (1) to always (5) - they use a certain travel mode (car; public transport (abbreviated as PT); cycling; and walking). Almost half of the respondents (i.e., 46.3\%) indicates that they frequently or always (i.e., a score of 4 or 5 on the five point scale) cycle for commute trips; $38.3 \%$ frequently or always uses the car, while the user frequency is lowest for public transport and walking ( $27.2 \%$ and $25.2 \%$, respectively).

\subsubsection{Travel attitudes}

In order to measure attitudes towards travel - and specific travel modes in particular - we asked respondents to which extent they agree with fourteen statements regarding the liking towards (the use of) car, public transport, cycling and walking, on a scale from 1 (totally disagree) to 5 (totally agree). Based on a factor analysis (principal axis factoring; promax rotation), two factors - explaining $44.3 \%$ of the total variance - can be identified: Pro sustainable travel (explaining $31.7 \%$ ) and Pro car (explaining 12.6\%) (Table 3). 
Table 3. Factors for travel attitudes

\begin{tabular}{llc}
\hline Factor & Statement ${ }^{\text {a }}$ & Loading $^{\text {b }}$ \\
\hline Pro sustainable travel & Destinations should be well accessible by bike & 0.77 \\
& Streets should be walk friendly & 0.74 \\
& Destinations should be well accessible on foot & 0.72 \\
& Neighbourhoods should be bike friendly & 0.51 \\
& Cities should be low-traffic areas & 0.41 \\
& More investment in public transport is needed & 0.35 \\
& I like to cycle & 0.29 \\
& I like to walk & 0.28 \\
\hline Pro car & I need a car to feel free & 0.83 \\
& I like driving a car & 0.78 \\
& City centers should be/should remain well accessible by car & 0.71 \\
Car use should be taxed more heavily & -0.56 \\
Cities should be low-traffic areas & -0.41 \\
& I like using public transport & -0.37 \\
& Public transport is unreliable & 0.29 \\
\hline
\end{tabular}

${ }^{a}$ In order to improve readability, only statements with a factor loading greater than 0.25 in magnitude are shown.

${ }^{\mathrm{b}}$ Represents the degree of association between the statement and the factor.

\subsubsection{Self-reported change in travel behaviour and mode-specific attitudes}

Respondents were asked to indicate how frequently they now use various travel modes for their daily commute compared to before the relocation, on a five-point scale from -2 (far less frequent) to +2 (far more frequent). Respondents were also asked to indicate how their average commute distance changed after their relocation on a five-point scale from -2 (a lot shorter) to +2 (a lot longer). Changes in car possession were measured by asking respondents' their car possession before and after the relocation. Finally, we asked respondents to indicate on a five-point scale what their current stance is towards car use, public transport use, cycling and walking compared to before the relocation, from -2 (far more negative) to +2 (far more positive).

\subsubsection{Socio-demographic variables}

The following socio-demographic variables have been included into the multinomial logistic regressions analysing changes in mode frequency and travel attitudes (see Sections 4.2 and 4.3 ): respondents' age (in years), gender ( $0=$ male; $1=$ female), educational attainment ( $0=$ low education (secondary school degree or less); $1=$ high education (college or university degree)), monthly net household income ( 0 = low household income (lower than 2,500€ per month); $1=$ high household income (at least 2,500€ per month)), children younger than eighteen living at home ( $0=$ no; $1=$ yes), driving license ( $0=$ no; $1=$ yes), and household car possession (amount of cars).

\section{Results}

\subsection{Travel attitudes and mode choice according to respondents' current and previous neighbourhood}

Respondents' travel mode choice and attitudes differ according to the neighbourhood they live in. In line with previous studies, we found significantly higher car use for suburban residents than for urban 
residents (at $\mathrm{p}<0.05)^{5}$, i.e., $54.8 \%$ of suburban residents frequently uses the car, while this is only $29.9 \%$ for urban residents. Frequent public transport use, cycling and walking, on the other hand, is significantly higher for urban residents than for suburban residents (at $\mathrm{p}<0.05$; respectively $32.4 \%$, $51.1 \%$, and $33.0 \%$ for urban residents and $16.9 \%, 37.0 \%$ and $9.8 \%$ for suburban residents). These results indicate that travel mode choice is associated with the respondents' residential neighbourhood. Additionally, we also found significant differences in travel attitudes according to the residential location. Urban residents have, on average, significantly higher scores on the pro sustainable travel factor (at $p<0.05 ; 0.06$ versus -0.11 for suburban residents), while suburban residents have significantly higher scores on the pro car factor (at $p<0.05 ; 0.25$ versus -0.13 for urban residents). As our respondents only relocated recently, this suggests that travel preferences and attitudes have a large impact on the residential location choice. However, it might also be possible that people have adapted their attitudes to their new residential environment, even in a short time frame (see Section 4.3).

Besides a rather clear effect of the residential neighbourhood on travel mode choice and travel attitudes, it might also be possible that the previous residential environment influences travel behaviour and attitudes. Figure 4 and Table 4 suggest that travel mode choice and travel-related attitudes are not only associated with the current residential neighbourhood, but also with the previous neighbourhood. For car use, we noted that suburban residents relocated from a suburbanstyle neighbourhood travel significantly more by car than their suburban counterparts relocated from a more urban neighbourhood (at $p<0.05$; for $p$-values of ANOVA post-hoc multiple comparison analysis, see Appendix A). Urban residents coming from a less urban neighbourhood travel significantly more by car than urban residents previously residing in a similar-style neighbourhood. A similar, yet opposite, effect can be found for cycling; urban residents previously residing in urban-style neighbourhoods travel more frequently by bike than urbanites coming from a more suburban neighbourhood, while suburban residents previously residing in a similar-type neighbourhood travel less frequent by bike compared to suburban residents coming from an urban-type neighbourhood (although the latter two groups do not significantly differ from each other at $p<0.05$ ). For public transport use, we see a similar (yet non-significant) effect for urban residents, but not for suburban residents, where the use of public transport seems independent from the previous residential neighbourhood. Finally, the frequency of walking is not significantly affected by respondents' previous neighbourhood. These differences in travel mode choice can be partly explained by varying levels of car possession, which is highest for suburban residents coming from suburban-style neighbourhoods (1.32) and lowest for urban residents coming from urban neighbourhoods (0.75); while respondents moving to different types of neighbourhoods have intermediate levels of car possession (i.e., 1.24 for suburban residents and 0.85 for urban residents). This might suggest that households do not always directly buy or sell (when moving to suburban or urban neighbourhood, respectively) a car after a relocation, which might delay potential mode changes after a relocation.

Besides mode choice, travel-related attitudes also seem to be affected by respondents' previous residential location. Suburban residents previously residing in a suburban-style neighbourhood have somewhat - yet non-significantly - lower scores on the pro sustainable travel factor and significantly higher scores on the pro car factor compared to suburban residents previously living in more urban

\footnotetext{
${ }^{5}$ Comparisons of means made in this paragraph are based on two-sample t-tests.
} 
neighbourhoods. Similar - yet opposite - results can be found for urban residents. Urban residents previously residing in an urban-style neighbourhood have somewhat - albeit non-significantly - higher scores on the pro sustainable travel factor and significantly lower scores on the pro car factor compared to urban residents previously residing in less urban neighbourhoods (for $p$-values of ANOVA post-hoc analysis, see Appendix B). These results seem to indicate that the previous residential location (and the travel behaviour and attitudes formed over there) may exert an influence on people's current travel mode choice and travel attitudes. This suggests that attitudes and behaviour may linger for longer periods, even if the context corresponds with other attitudes and behaviour.

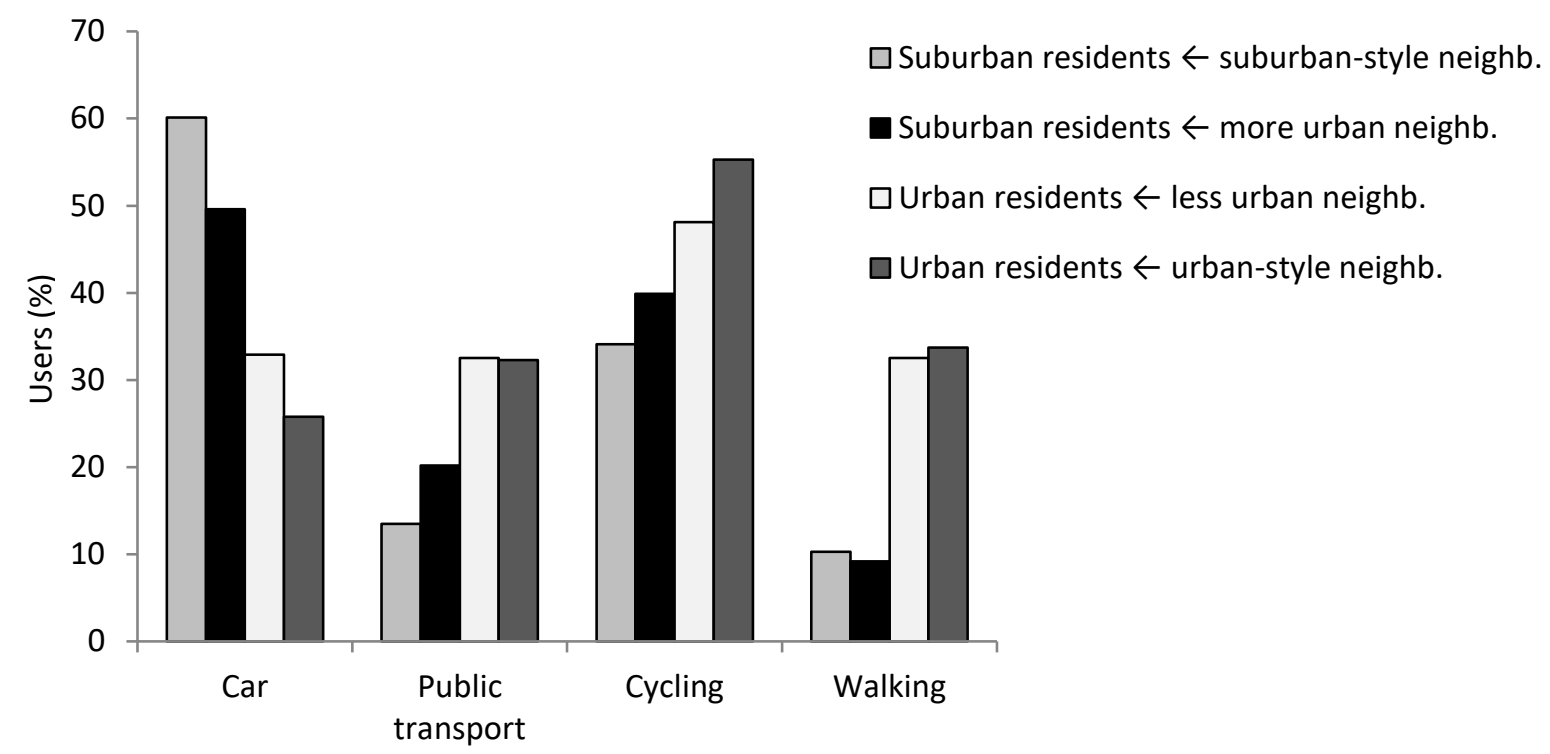

Figure 4. Frequent travel mode use within groups of similar types of current and previous neighbourhoods.

Table 4. Average factor scores of the four groups with similar types of current and previous neighbourhoods.

\begin{tabular}{lcc}
\hline & Pro sustainable travel & Pro car \\
\hline Suburban resident $\leftarrow$ suburban-style neighb. & -0.17 & 0.34 \\
Suburban resident $\leftarrow$ more urban neighb. & -0.06 & 0.17 \\
Urban resident $\leftarrow$ less urban neighb. & 0.03 & -0.06 \\
Urban resident $\leftarrow$ urban-style neighb. & 0.10 & -0.23 \\
\hline
\end{tabular}

\subsection{Change in mode frequency}

A potential change in the frequency of travel mode use for commuting is initially measured retrospectively, by asking respondents to which extent they changed the frequency of mode use after their relocation (Table 5). Urban respondents previously living in suburban-style neighbourhoods indicate the highest levels of change in the frequency of mode use. Public transport use, cycling and especially walking has significantly increased since the relocation, while car use seems to have decreased. A similar, yet opposite and somewhat less strong change seems to occur for suburban residents previously living in a more urban neighbourhood. Self-reported changes in the frequency of mode use for suburban and urban residents previously living in a similar residential environment is rather modest. These changes in mode frequency can be partly explained by changes in average travel 
distance and household car possession. The largest reduction in both travel distance and car possession can be found for urban residents previously living in less urban neighbourhoods, while suburban residents coming from more urbanised neighbourhoods is the only group that, on average, does not see a decrease in travel distance and car possession. The fact that for most respondents commute distance (and car use) decreases is not that surprising as living closer to the job location can be an important reason to relocate. In our sample, 434 respondents $(28.2 \%)$ indicate that they relocated for work-related reasons; 110 (7.1\%) because they have a new job (location), 222 (14.4\%) in order to live closer to their job, and $102(6.6 \%)$ for a combination of these two reasons. As a result, we also see a significant decrease in car use and increase in public transport use and active travel for all respondents combined, independent from their current and previous residential location.

Table 5. Self-reported change in mode frequency, travel distance and car possession. Bold = significantly different from 0 (i.e., no change) at $p<0.05$ (based on one-sample t-tests).

\begin{tabular}{lcccc|cc}
\hline & $\begin{array}{c}\text { Change } \\
\text { in car } \\
\text { freq. }\end{array}$ & $\begin{array}{c}\text { Change } \\
\text { in PT } \\
\text { freq. }\end{array}$ & $\begin{array}{c}\text { Change } \\
\text { in cycling } \\
\text { freq. }\end{array}$ & $\begin{array}{c}\text { Change in } \\
\text { walking } \\
\text { freq. }\end{array}$ & $\begin{array}{c}\text { Change in } \\
\text { commute } \\
\text { distance }\end{array}$ & $\begin{array}{c}\text { Change } \\
\text { in car } \\
\text { poss. }\end{array}$ \\
\hline Sub. resident $\leftarrow$ sub.-style neighb. & $-\mathbf{0 . 1 6}$ & 0.10 & 0.11 & $\mathbf{0 . 1 6}$ & $-\mathbf{0 . 1 4}$ & -0.16 \\
Sub. resident $\leftarrow$ more urban neighb. & $\mathbf{0 . 1 5}$ & -0.07 & -0.07 & $-\mathbf{0 . 3 2}$ & $\mathbf{0 . 4 4}$ & 0.04 \\
Urban resident $\leftarrow$ less urban neighb. & $-\mathbf{0 . 5 2}$ & $\mathbf{0 . 1 6}$ & $\mathbf{0 . 3 9}$ & $\mathbf{0 . 7 5}$ & $-\mathbf{0 . 6 7}$ & $-\mathbf{0 . 2 5}$ \\
Urban resident $\leftarrow$ urban-style neighb. & $\mathbf{- 0 . 1 5}$ & 0.00 & 0.07 & $\mathbf{0 . 2 4}$ & $\mathbf{- 0 . 1 0}$ & -0.04 \\
\hline Total & $-\mathbf{0 . 2 4}$ & $\mathbf{0 . 0 7}$ & $\mathbf{0 . 1 7}$ & $\mathbf{0 . 3 2}$ & $\mathbf{- 0 . 2 3}$ & $-\mathbf{0 . 1 2}$ \\
\hline
\end{tabular}

In order to analyse which factors influence a change in car use, public transport use, cycling and walking, we performed four multinomial logistic regressions (Table 6). In these regressions we compare a decrease (i.e., strongly decreased (score: -2) and decreased (score: -1) combined) and an increase in use (i.e., increased (score: 1 ) and strongly increased (score: 2) combined) with no changes in use as reference category (score: 0 ). These regressions indicate that a (self-reported) change in mode use is highly affected by a change in the level of urbanization, independent from other elements. Relocating to a more urban-style neighbourhood, results in less car use and more public transport use and active travel. Furthermore, results also indicate that people who frequently use a certain travel mode often have witnessed an increase in the use of that mode (since relocating), and that an improved (or worsened) attitude towards a certain mode increases (or decreases) its use. A decrease in commute distance and car possession seem to discourage car use and stimulate active travel. The effect of socio-demographics on changes in mode frequency following a relocation seems rather modest. 
Table 6. Multinomial logistic regressions for change in car use, PT use, cycling and walking (reference category $=$ no change) . Bold $=$ significant a $p<0.01$; underlined $=$ significant at $0.01 \leq p<0.05$; regular $=$ significant at $0.05 \leq p<0.10$; coefficient not presented $=$ not significant at $p<0.10$.

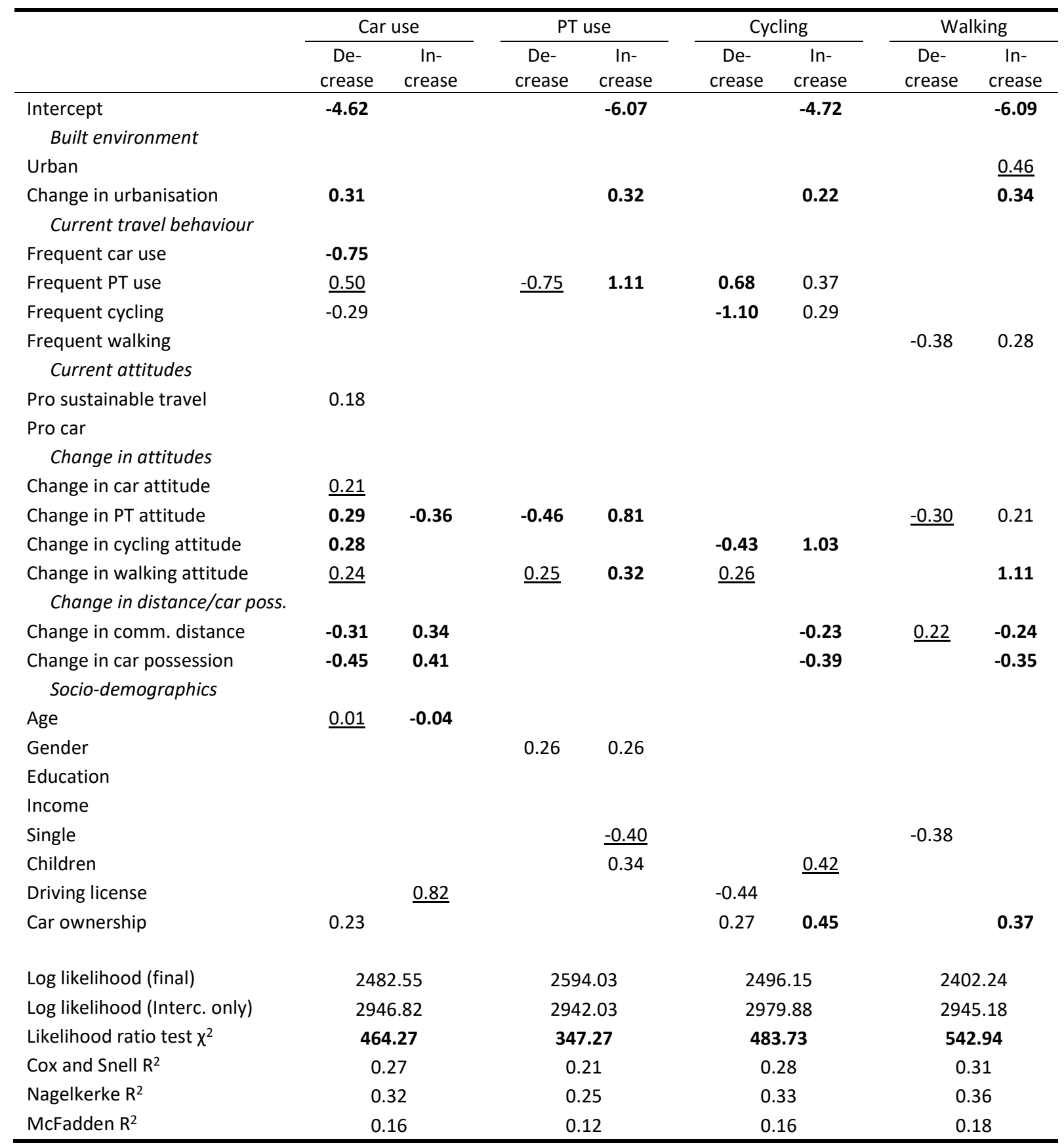

Although Tables 5 and 6 provide interesting insights into changes in mode choice after a relocation, it does not indicate when these changes occur, i.e., right after the residential move has occurred, or gradually in the period following the relocation. We therefore analysed the frequency of travel mode use according to (i) their current and previous type of neighbourhood and (ii) the duration of residence in the new neighbourhood (Figure 5). 


\section{Suburban residents}

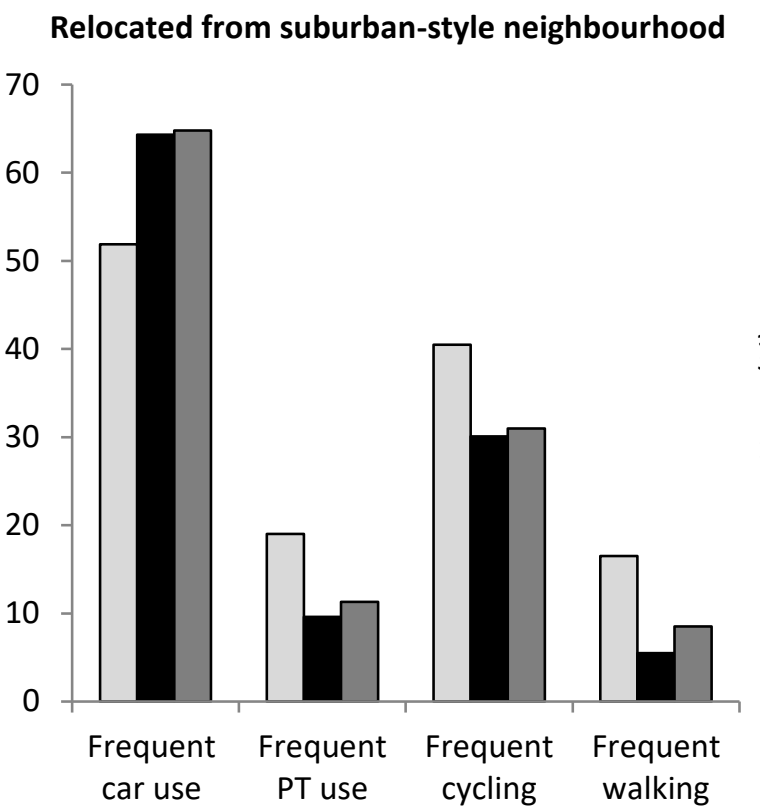

\section{Relocated from more urban neighbourhood}
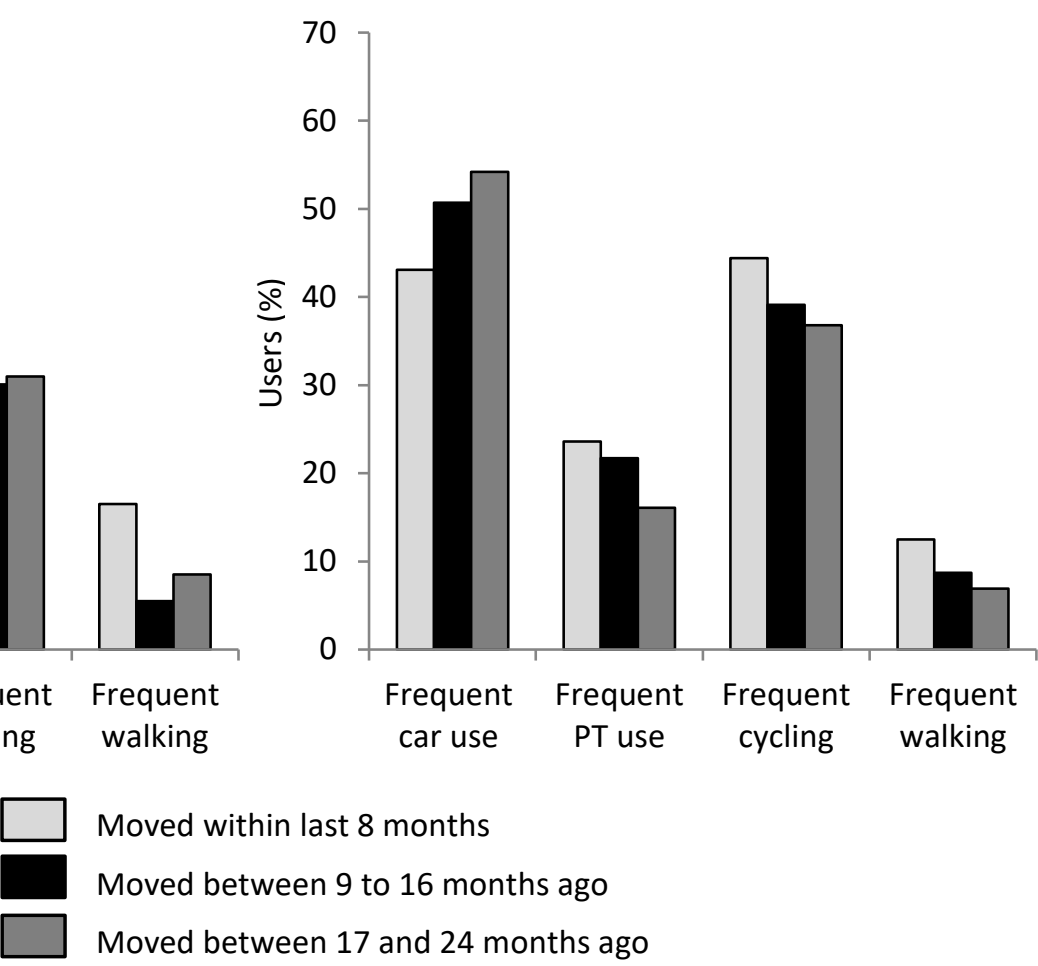

\section{Urban residents}
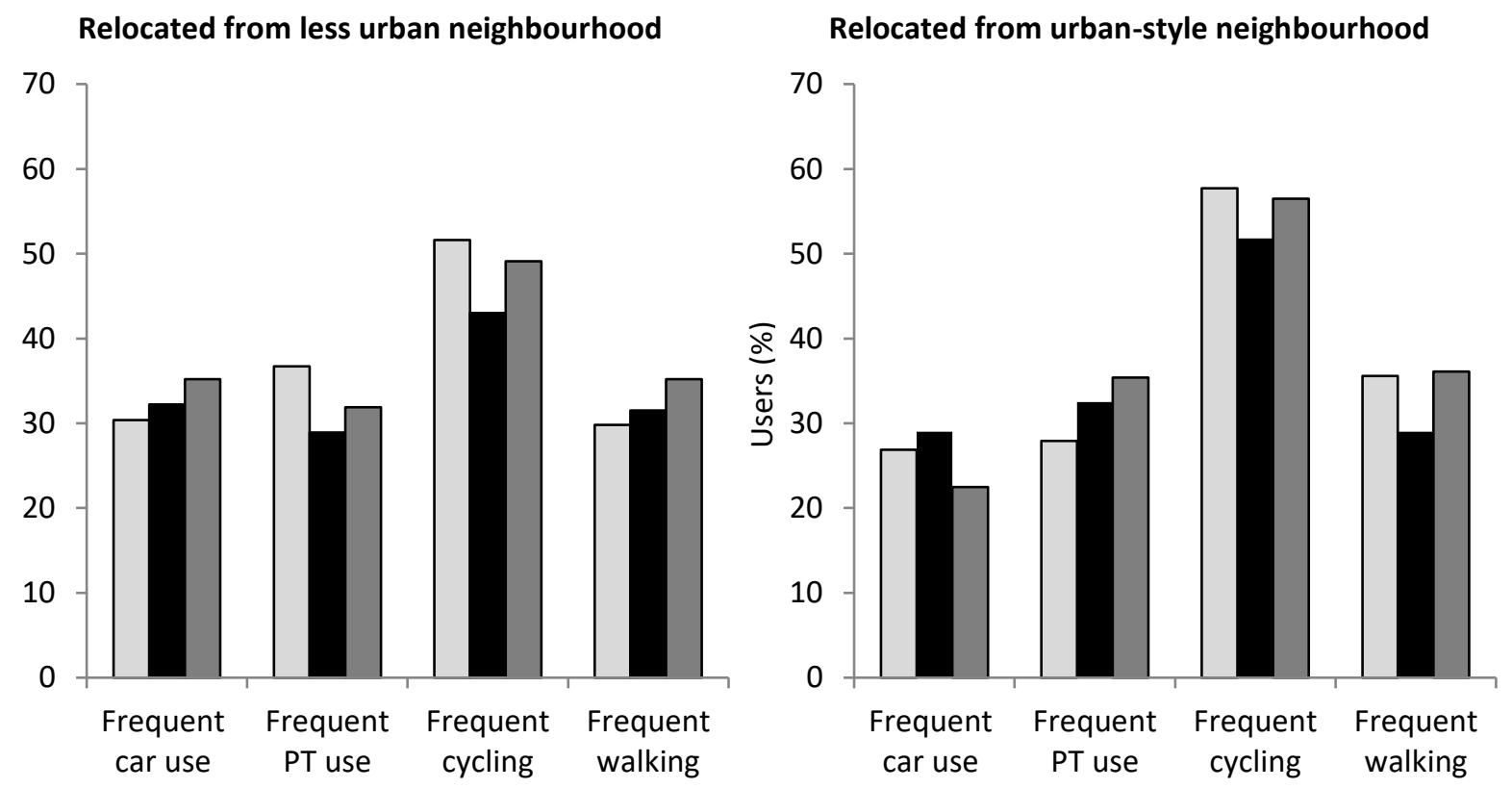

Figure 5. Frequent travel mode use according to current and previous neighbourhood and moment of relocation.

Although we did not find any significant differences in mode frequency for the four groups according to the moment of relocation (for p-values of ANOVA post-hoc analysis, see Appendix C) a certain trend 
for suburban respondents can be observed. ${ }^{6}$ For the suburban residents relocated from a suburbanstyle neighbourhood we can see a certain increase in car use frequency and a decrease in the frequency in public transport use, cycling and walking between the group that most recently relocated and the two other groups. For the suburban residents moving from a more urban neighbourhood, we see a steady increase in car use frequency and decrease in the frequency of public transport use, cycling and walking going from the respondents relocated most recently and those relocated the longest time ago. For both groups of urban respondents, we do not see a clear pattern in the evolution of mode use frequency.

Results from Table 5 and Figure 5 do not seem to match with each other. For instance, while Table 5 indicates a relatively strong change in mode frequency of urban respondents moving from a less urban neighbourhood, these self-reported changes are not observed in Figure 5. This can be explained by the fact that the self-reported change in mode frequency measures the difference between before and after the relocation, while the comparison between the three groups of respondents relocating within a certain time frame analyses an evolution after the relocation has taken place. Keeping this and the necessary caution - in mind, this suggests that urban residents who moved from a less urban neighbourhood change their mode frequency directly after the relocation, while a change in mode frequency happens more steadily for suburban residents, especially those moving from a more urban neighbourhood.

\subsection{Change in travel attitudes}

Parallel to changes in mode frequency, changes in travel attitudes are measured in two ways. First of all, we asked respondents to indicate what their current stance is towards car use, public transport use, cycling and walking compared to before the relocation. The largest self-reported changes in attitudes can be found for the urban residents previously living in a less urban neighbourhood. Mainly their attitudes towards cycling and especially walking have improved most. For respondents in the other three groups, changes in attitudes seem less strong, although improvements in attitudes towards all modes (except for walking attitudes of suburban residents moving from more urban neighbourhood) can be noticed (Table 7). A possible explanation is that a residential relocation creates a new context in which certain travel-related choices are likely to be reconsidered (Verplanken et al., 2008). The use of a certain travel mode might not have been an option before the relocation (e.g., due to habitual use of another mode), but might be considered and valued after the relocation took place.

Table 7. Self-reported changes in mode-specific attitudes. Bold = significantly different from 0 (i.e., no change) at $p<0.05$ (based on one-sample t-tests).

\begin{tabular}{lcccc}
\hline & $\begin{array}{c}\text { Change in car } \\
\text { attitude }\end{array}$ & $\begin{array}{c}\text { Change in PT } \\
\text { attitude }\end{array}$ & $\begin{array}{c}\text { Change in } \\
\text { cycling } \\
\text { attitude }\end{array}$ & $\begin{array}{c}\text { Change in } \\
\text { walking } \\
\text { attitude }\end{array}$ \\
\hline Sub. Resident $\leftarrow$ sub.-style neighb. & $\mathbf{0 . 1 0}$ & $\mathbf{0 . 1 7}$ & $\mathbf{0 . 2 6}$ & $\mathbf{0 . 2 1}$ \\
Sub. Resident $\leftarrow$ more urban neighb. & 0.05 & 0.03 & $\mathbf{0 . 1 9}$ & -0.03 \\
Urban resident $\leftarrow$ less urban neighb. & $\mathbf{0 . 1 4}$ & $\mathbf{0 . 1 8}$ & $\mathbf{0 . 4 5}$ & $\mathbf{0 . 8 0}$ \\
Urban resident $\leftarrow$ urban-style neighb. & 0.02 & 0.04 & $\mathbf{0 . 2 0}$ & $\mathbf{0 . 3 2}$ \\
\hline Total & $\mathbf{0 . 0 9}$ & $\mathbf{0 . 1 1}$ & $\mathbf{0 . 3 1}$ & $\mathbf{0 . 4 3}$ \\
\hline
\end{tabular}

\footnotetext{
${ }^{6}$ Note that the insignificant differences in mode frequency between the different groups of respondents can be partly explained by the relatively small sizes of subsamples.
} 
In order to analyse which factors influence attitude changes towards car use, public transport use, cycling and walking following a residential relocation, we performed four multinomial logistic regressions (Table 8). In these regressions we compare a deterioration (i.e., strongly deteriorated (score: -2) and deteriorated (score: -1) combined) and an improvement (i.e., improved (score: 1) and strongly improved (score: 2) combined) in mode-specific attitudes with no changes in attitudes as reference category (score: 0 ). Results indicate that moving to a more urbanised neighbourhood has positive effects on attitudes towards all travel modes, but especially on attitudes towards public transport use and active travel. Furthermore, we also see that an increased (or decreased) use of a certain mode has a positive (or negative) effect on attitudes towards these modes, although no such effects are found for car use and car attitudes. The effects of current travel attitudes, changes in commute distance and car possession, and socio-demographics on changes in mode-specific attitudes are rather limited. 
Table 8. Multinomial logistic regressions for change in attitudes towards car use, PT use, cycling and walking (reference category $=$ no change). Bold $=$ significant a $p<0.01$; underlined $=$ significant at 0.01 $\leq p<0.05$; regular $=$ significant at $0.05 \leq p<0.10$; coefficient not presented $=$ not significant at $p<$ 0.10 .

\begin{tabular}{|c|c|c|c|c|c|c|c|c|}
\hline & \multicolumn{2}{|c|}{ Car attitude } & \multicolumn{2}{|c|}{ PT attitude } & \multicolumn{2}{|c|}{ Cycling attitude } & \multicolumn{2}{|c|}{ Walking attitude } \\
\hline & $\begin{array}{c}\text { Worse } \\
\text { ned }\end{array}$ & $\begin{array}{l}\text { Impro } \\
\text { ved }\end{array}$ & $\begin{array}{c}\text { Worse } \\
\text { ned }\end{array}$ & $\begin{array}{c}\text { Impro } \\
\text { ved }\end{array}$ & $\begin{array}{c}\text { Worse } \\
\text { ned }\end{array}$ & $\begin{array}{c}\text { Impro } \\
\text { ved }\end{array}$ & $\begin{array}{c}\text { Worse } \\
\text { ned }\end{array}$ & $\begin{array}{c}\text { Impro } \\
\text { ved }\end{array}$ \\
\hline \multicolumn{9}{|l|}{ Built environment } \\
\hline Urban & & & & & & & & 0.74 \\
\hline \multicolumn{9}{|l|}{ Current travel behaviour } \\
\hline Frequent car use & & & & & & $\underline{-0.37}$ & & \\
\hline Frequent PT use & & & & $\underline{0.45}$ & & & & \\
\hline Frequent cycling & & & & & -1.38 & 0.29 & & \\
\hline \multicolumn{8}{|l|}{ Current attitudes } & 0.45 \\
\hline Pro sustainable travel & & 0.18 & & & & & & \\
\hline \multicolumn{9}{|l|}{ Change in travel behaviour } \\
\hline Change in car use & & & & $\underline{-0.18}$ & & & & \\
\hline Change in PT use & & & -0.40 & 0.65 & & & & \\
\hline Change in cycling & & 0.17 & 0.20 & & -0.34 & 0.91 & & \\
\hline \multicolumn{8}{|l|}{ Change in distance/car poss. } & 0.67 \\
\hline Change in comm. distance & & & & & 0.28 & & 0.44 & -0.25 \\
\hline \multicolumn{9}{|l|}{ Socio-demographics } \\
\hline Age & $\underline{-0.02}$ & & $\underline{-0.02}$ & & & & $\underline{0.02}$ & \\
\hline Gender & & & & & $\underline{0.51}$ & 0.34 & & \\
\hline Education & $\underline{-0.57}$ & $\underline{-0.42}$ & & & & & & \\
\hline Income & & -0.52 & $\underline{-0.42}$ & & & & & -0.29 \\
\hline Single & & & & & -0.48 & & & \\
\hline Children & & & & & & 0.30 & 0.50 & \\
\hline \multicolumn{9}{|l|}{ Driving license } \\
\hline Car ownership & 0.46 & 0.54 & & & & 0.22 & & \\
\hline Log likelihood (final) & \multicolumn{2}{|c|}{2092.05} & \multicolumn{2}{|c|}{2142.58} & \multicolumn{2}{|c|}{2182.66} & \multicolumn{2}{|c|}{2024.98} \\
\hline Log likelihood (Interc. only) & \multicolumn{2}{|c|}{2234.44} & \multicolumn{2}{|c|}{2461.84} & \multicolumn{2}{|c|}{2601.17} & \multicolumn{2}{|c|}{2535.19} \\
\hline Likelihood ratio test $\chi^{2}$ & \multicolumn{2}{|c|}{142.39} & \multicolumn{2}{|c|}{319.27} & \multicolumn{2}{|c|}{418.54} & \multicolumn{2}{|c|}{510.21} \\
\hline Cox and Snell $\mathrm{R}^{2}$ & \multicolumn{2}{|c|}{0.10} & \multicolumn{2}{|c|}{0.20} & \multicolumn{2}{|c|}{0.25} & \multicolumn{2}{|c|}{0.30} \\
\hline Nagelkerke $\mathrm{R}^{2}$ & \multicolumn{2}{|c|}{0.12} & \multicolumn{2}{|c|}{0.24} & & & & \\
\hline McFadden $\mathrm{R}^{2}$ & & & & & & & & \\
\hline
\end{tabular}

In order to get an indication of how travel attitudes evolve after a relocation, we analyse average factor scores of the pro sustainable travel factor and pro car factor according to current and previous neighbourhood and moment of relocation (Figure 6). The most clear - and only significant - trend can be noticed for suburban residents (for p-values of ANOVA post-hoc analysis, see Appendix D). ${ }^{7}$ For suburban residents relocated from a suburban-style neighbourhood, we notice a significant increase

\footnotetext{
${ }^{7}$ Note that the insignificant differences in travel attitudes between the different groups of respondents can be partly explained by the relatively small sizes of subsamples.
} 
- from most recent relocated respondents to least recent relocated respondents - in the pro car attitude and a (non-significant) decrease in the pro sustainable travel attitude. For suburban residents relocated from a more urban neighbourhood we see a similar, significant trend in the pro car attitude, but not so much in the pro sustainable travel attitude. Travel attitudes seem less subject to change for urban respondents. Although a slight, but non-significant, improvement in attitudes (mainly the pro sustainable travel attitude) can be found for urban respondents relocated from a less urban neighbourhood, no trend in attitudes can be found for urban respondents relocated from an urbanstyle neighbourhood.

Similar to changes in mode frequency, we see that self-reported change in attitudes (Table 7) differs from the evolution in attitudes measured by a comparison of three groups according to the moment of relocation (Figure 6). While self-reported changes in attitudes are largest for urban respondents coming from a less urban neighbourhood, the comparison between three groups of respondents with various moments of relocation suggests that the strongest changes in attitudes occur for suburban respondents. This could suggest that an attitude change happens rather suddenly for non-urbanites moving to an urban neighbourhood and only changes steadily for people moving to a suburban neighbourhood.

The fact that pro sustainable travel and pro car values are similar for the most recently relocated respondents moving to a different type of neighbourhood (i.e., group A of the second and third group) suggests that attitudes are not always as important in the residential location choice as indicated in most residential self-selection studies. People moving to different type of neighbourhoods do not seem to have a pronounced preference for a certain type of travel. Yet, after living in the new neighbourhood for a while, people seem to adapt their attitudes towards the environment, at least when residing in suburban neighbourhoods. For recently moved respondents moving to similar type of neighbourhood (i.e., the first and fourth group) levels of pro sustainable travel and pro car values are noticeably different from each other indicating that these respondents have developed their travel attitudes in their previous, similar neighbourhood. The fact that respondents coming from a suburbanstyle neighbourhood have higher pro car attitudes and lower pro sustainable travel attitudes when relocating to a similar type of neighbourhood (group 1) than when relocating to more urban neighbourhood (group 3) suggests that attitudes still play a role. Similar results can be found for respondents coming from an urban-style neighbourhood; those moving to a similar neighbourhood (group 4) have lower pro car attitudes and higher pro sustainable travel attitudes than those moving to a less urban neighbourhood (group 2). In sum, results seem to suggest that travel attitudes have a certain effect on the residential location choice, and that especially people with strong attitudes tend to select themselves in preferred neighbourhoods. On the other hand, the residential location also partly seems to strengthen attitudes towards the mode(s) stimulated by the physical characteristics of the neighbourhood. This might suggest that the condition of residential dissonance is partly temporal and reduces over time. 


\section{Suburban residents}

Relocated from suburban-style neighbourhood

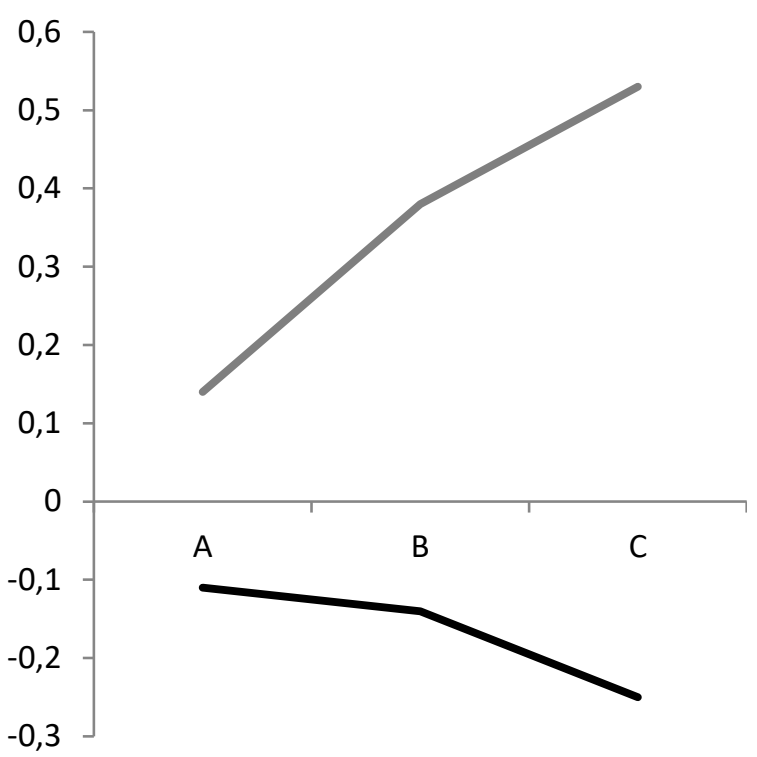

Relocated from more urban neighbourhood

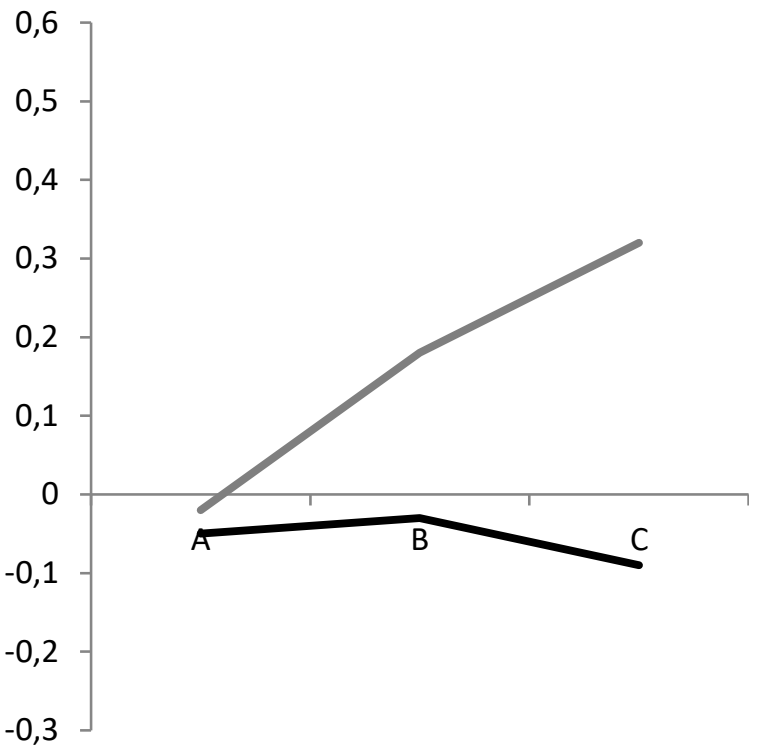

A: Moved within last 8 months

B: Moved between 9 to 16 months ago

C: Moved between 17 and 24 months ago

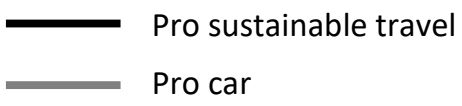

\section{Urban residents}

Relocated from less urban neighbourhood

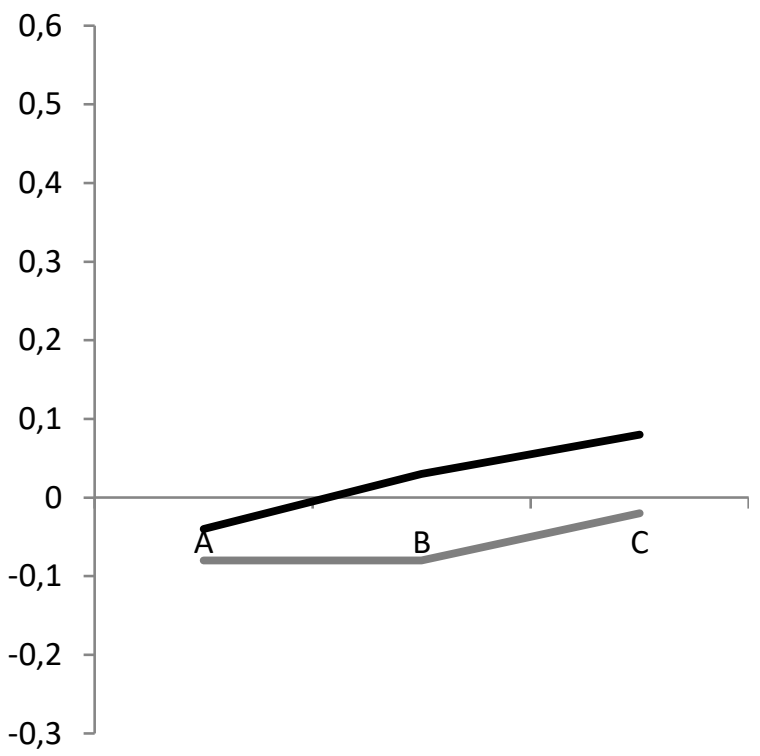

Relocated from urban-style neighbourhood

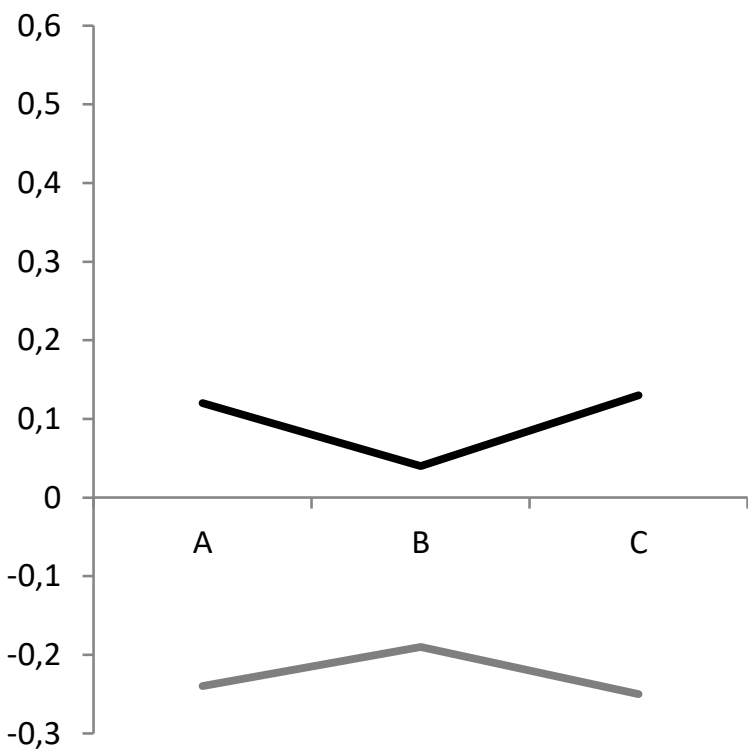

Figure 6. Travel attitudes (factor scores) according to current and previous neighbourhood and moment of relocation.

\section{Discussion and conclusion}

Results from this partly quasi-longitudinal/retrospective study indicate that both mode choice and attitudes change after a residential relocation. Urban residents - especially those coming from less 
urbanised neighbourhoods - indicate that they walk, cycle, and use public transport more often and travel less by car, and also that their attitudes towards active travel and public transport has improved since the relocation. Suburban residents report less change in their mode frequency and attitudes. Only suburban residents previously living in more urbanised areas indicate that they travel more by car and walk less. Suburban residents do not indicate considerable change in attitudes. We also found (self-reported) changes in mode frequency and attitudes independent from the current and previous neighbourhood. On average, respondents indicated a significant decrease in car use and increase in public transport use and active travel (possibly since a substantial part of the respondents (i.e., 28.2\%) indicated that they relocated in order to live closer to their job) and strong improvements of attitudes towards active travel. Results from multinomial logistic regressions show that moving to a more urban neighbourhood reduces car use and increase public transport use and active travel, while also improving attitudes towards public transport and active travel (while controlling for other confounding factors). Additionally, these regression analyses also suggest that an improved stance towards a certain travel mode (following a relocation) results in an increased use of that mode, and vice versa.

We also analysed travel mode frequency and travel attitudes of respondents relocating (i) within the last 8 months, (ii) between 9 and 16 months ago, and (iii) longer than 16 months ago, in order to get insights in evolutions of mode frequency and attitudes. Results of this method suggest that mode frequency and especially attitudes gradually change after a relocation, but mainly for suburban residents. Although no significant differences in mode frequency were found, suburban respondents already living in their neighbourhood for more than 8 months walk, cycle and use public transport less often and use the car more often compared to those living in suburban neighbourhoods for maximum 8 months. Attitudes of suburban residents towards car use, on the other hand, are significantly more positive for respondents already living in their neighbourhood for more than 8 months compared to more recent movers. For urban residents we did not find considerable differences in mode frequency and attitudes according to the length of residence.

To the best of our knowledge, only the study of Wang and Lin (2018) has analysed travel attitudes before and after a residential relocation, albeit with far less respondents and measuring travel preferences in limited detail. They found (i) that travel preferences pre-move did not affect the built environment post-move (suggesting limited self-selection effects), and (ii) significant changes in travel preferences before and after a relocation. Results of our study are only partly in line with the findings of Wang and Lin (2018). We find that attitudes do play a certain role in the decision where to reside (suggesting substantial self-selection effects), and that attitudes gradually change after a residential relocation. These reciprocal influences between the built environment and travel attitudes are in line with recent studies (de Abreu e Silva, 2014; Ewing et al., 2016; Lin et al., 2017; Van Acker et al., 2014). Results also show that - at least for suburban residents - attitudes gradually become more in line with the new residential environment, possibly due to an increased use of modes stimulated by the new environment. This suggests that residential dissonance, which mainly occurs for people moving to a different type of neighbourhood, can reduce over time and that residential dissonance is often a temporal situation. This can be partly explained by the theory of cognitive dissonance (Festinger, 1957). According to this theory, people will try to reduce feelings of discomfort associated with a dissonance between attitudes and behaviour. This can be realised by changing behaviour or by changing attitudes. Since a relocation generally brings along considerable monetary as well as 
nonmonetary costs and since the respondents in our survey already relocated recently, a change in travel-related attitudes might be a more obvious way to reduce residential dissonance.

Results found in this study - mainly from respondents' self-reported changes in mode frequency and attitudes - are consistent with the idea that more people living in/moving to urban-style neighbourhoods result in more sustainable travel patterns. This study suggests that an urban environment will not only stimulate active travel and public transport use due to its physical characteristics (i.e., high density and diversity), but also because it can considerably improve attitudes towards these modes. As a result, policy makers and urban planners should create additional dwellings in urban settings by either creating new compact, mixed-use neighbourhoods, or by increasing density and diversity in existing neighbourhoods. Since attitudes have an important impact on travel behaviour, changing these attitudes through adaptations of the built environment can be an important way to change people's travel behaviour in a desired way.

Our study has also a number of limitations. Since the results are based on self-reported changes in mode frequency and travel attitudes, and on a cohort approach to look at mode frequency and attitudes at different times after a relocation, this study only provides a certain indication of changes in mode use and attitudes. Although having a large sample size and high level of detail, this study should consequently be regarded as an exploratory study. First of all, future studies using a cohort approach will benefit from even larger sample sizes as this will result in more reliable comparisons between subsamples. In this study, changes in mode frequency and attitudes between subsamples were often not significant, possibly due to relatively small subsamples. Second, in order to fully capture evolutions in travel behaviour and attitudes, studies adopting a longitudinal design are necessary, preferably measuring behaviour and attitudes before, directly after and a certain period of time after a relocation has taken place. In this regard, longitudinal (national) household surveys with a large sample, multiple waves and sufficient (attitudinal) travel questions might be valuable. Using such data will make it possible to analyse whether travel preferences and travel behaviour change differently after a relocation for people choosing their residential location based on travel preferences (i.e., residential self-selection) and those with limited freedom in choosing their residential location (i.e., residential determination), as is presented in Figures 1 and 2. Furthermore, this might provide insights into how long the previous residential location exerts an influence on people's current travel behaviour and attitudes, and whether changes in travel behaviour and attitudes after a relocation happen faster for urban residents than for suburban residents, as is suggested by our results.

Future studies should also look at whether (potential) changes in attitudes are caused by the new residential environment itself, or by the new travel patterns stimulated by the new place of residence, which cannot be clarified in this study. The new built environment can potentially change people's attitudes resulting in changing travel behaviour, just as it is feasible that the new residential location imposes new travel patterns on the new residents resulting in changing travel attitudes. Although results from the performed multinomial logistic regressions suggest bidirectional effects between increased use of a certain mode and improved attitudes towards that mode, no robust conclusions on the causal nature of processes can be drawn without true longitudinal data. On the other hand, it is also possible that changes in travel behaviour and attitudes happen simultaneously (Dobson et al., 1978; Golob, 2001; Kroesen et al., 2017; Tardiff, 1977), resulting in a possible self-reinforcing effect. Furthermore, it might also be valuable to look at the intermediate role of car possession. Car 
possession influences mode choice but is also affected by the residential location choice (Chen et al., 2008; Eluru et al., 2010; Van Acker \& Witlox, 2010). However, people might wait a certain amount of time before buying or selling a car after a residential relocation due to high (monetary) costs involved, possibly delaying changes in travel behaviour and attitudes. Anyhow, in order to fully capture relationships between (changing) travel behaviour, travel attitudes and the built environment, more complex methodologies, such as (crossed-lagged) structural equation models are necessary.

\section{Acknowledgements}

The authors would like to thank the three anonymous reviewers for their constructive comments and suggestions, making it possible to improve this article. This work was supported by the Research Foundation - Flanders (FWO) under grant 12F2519N.

\section{References}

Aditjandra, P.T., Cao, J., Mulley, C., 2016. Exploring changes in public transport use and walking following residential relocation: a British case study. Journal of Transport and Land Use 9 (3), 1-19.

Bagley, M.N., Mokhtarian, P.L., 2002. The impact of residential neighborhood type on travel behavior: a structural equations modeling approach. The Annals of Regional Science 36 (2), 279-297.

Bamberg, S., 2006. Is a residential relocation a good opportunity to change people's travel behavior? Results from a theory-driven intervention study. Environment and Behavior 38 (6), 820-840.

Cao, J., Ermagun, A., 2017. Influences of LRT on travel behaviour: A retrospective study on movers in Minneapolis. Urban Studies 54 (11), 2504-2520.

Cao, J., Ettema, D., 2014. Satisfaction with travel and residential self-selection: How do preferences moderate the impact of the Hiawatha Light Rail Transit line? Journal of Transport and Land Use 7 (3), 93-108.

Cao, J., Mokhtarian, P.L., Handy, S.L., 2009a. Examining the impacts of residential self-selection on travel behaviour: a focus on empirical findings. Transport Reviews 29 (3), 359-395.

Cao, J. Mokhtarian, P.L., Handy, S.L., 2009b. The relationship between the built environment and nonwork travel: a case study of Northern California. Transportation Research Part A 43 (5), 548-559.

Cervero, R., Kockelman, K., 1997. Travel demand and the 3Ds: density, diversity and design. Transportation Research Part D 2 (3), 199-219.

Chatman, D.G., 2009. Residential choice, the built environment, and nonwork travel: evidence using new data and methods. Environment and Planning A 41 (5), 1072-1089.

Chen, C., Gong, H., Paaswell, R., 2008. Role of the built environment on mode choice decisions: additional evidence on the impact of density. Transportation 35 (3), 285-299.

de Abreu e Silva, J., 2014. Spatial self-selection in land-use-travel behavior interactions: Accounting simultaneously for attitudes and socioeconomic characteristics. Journal of Transport and Land Use 7 (2), 63-84.

De Vos, J., Derudder, B., Van Acker, V., Witlox, F., 2012. Reducing car use: changing attitudes or relocating? The influence of residential dissonance on travel behavior. Journal of Transport Geography 22, 1-9. 
De Vos, J., Mokhtarian, P.L., Schwanen, T., Van Acker, V., Witlox, F., 2016. Travel mode choice and travel satisfaction: bridging the gap between decision utility and experienced utility. Transportation 43 (5), 771-796.

De Vos, J., Van Acker, V., Witlox, F., 2014. The influence of attitudes on Transit-Oriented Development: An explorative analysis. Transport Policy 35, 326-329.

De Vos, J., Witlox, F., 2013. Transportation policy as spatial planning tool; reducing urban sprawl by increasing travel costs and clustering infrastructure and public transportation. Journal of Transport Geography 33, 117-125.

De Vos, J., Witlox, F., 2016. Do people live in urban neighbourhoods because they do not like to travel? Analysing an alternative residential self-selection hypothesis. Travel Behaviour and Society 4, 29-39.

Dobson, R., Dunbar, F., Smith, C.J., Reibstein, D., Lovelock, C., 1978. Structural models for the analysis of traveler attitude-behavior relationships. Transportation 7 (4), 351-363.

Eluru, N., Bhat, C.R., Pendyala, R.M., Konduri, K.C., 2010. A joint flexible econometric model system of household residential location and vehicle fleet composition/usage choices. Transportation 37 (4), 603-626.

Ettema, D., Nieuwenhuis, R., 2017. Residential self-selection and travel behaviour: what are the effects of attitudes, reasons for location choice and the built environment? Journal of Transport Geography 59, 146-155.

Ewing, R., Cervero, R., 2001. Travel and the built environment: a synthesis. Transportation Research Record 1780, 87-114.

Ewing, R., Cervero, R., 2010. Travel and the built environment. A meta-analysis. Journal of the American Planning Association 76 (3), 265-294.

Ewing, R., Hamidi, S., Grace, J.B., 2016. Compact development and VMT-Environmental determinism, self-selection, or some of both? Environment and Planning B 43 (4), 737-755.

Fatmi, M.R., Habib, M.A., 2017. Modelling mode switch associated with the change of residential location. Travel Behaviour and Society 9, 21-28.

Festinger, L., 1957. Theory of Cognitive Dissonance. Stanford University Press, Stanford, CA.

Giles-Corti, B., Bull, F., Knuiman, M., McCormack, G., Van Niel, K., Timperio, A., Christian, H., Foster, S., Divitini, M., Middleton, N., Boruff, B., 2013. The influence of urban design on neighbourhood walking following residential relocation: longitudinal results from the RESIDE study. Social Science \& Medicine 77, 20-30.

Golob, T.F., 2001. Joint models of attitudes and behavior in evaluation of the San Diego I-15 congestion pricing project. Transportation Research Part A 35 (6), 495-514.

Groves, R.M., 1989. Survey errors and survey costs. John Wiley and Sons, New York.

Handy, S.L., Cao, J., Mokhtarian, P.L., 2005. Correlation or causality between the built environment and travel behavior? Evidence from Northern California. Transportation Research Part D 10 (6), 427444.

Kamruzzaman, M., Baker, D., Washington, S., Turrell, G., 2013. Residential dissonance and mode choice. Journal of Transport Geography 33, 12-28. 
Kamruzzaman, M., Washington, S., Baker, D., Brown, W., Giles-Corti, B., Turrell, G., 2016. Built environment impacts on walking for transport in Brisbane, Australia. Transportation 43 (1), 53-77.

Kitamura, R., Mokhtarian, P.L., Laidet, L., 1997. A micro-analysis of land use and travel in five neighborhoods in the San Francisco Bay Area. Transportation 24 (2), 125-158.

Klinger, T., Lanzendorf, M., 2016. Moving between mobility cultures: what affects the travel behaviour of new residents? Transportation 43 (2), 243-271.

Krizek, K.J., 2003. Residential relocation and change in urban travel. Journal of American Planning Association 69 (3), 265-281.

Kroesen, M., Handy, S., Chorus, C., 2017. Do attitudes cause behavior or vice versa? An alternative conceptualization of the attitude-behavior relationship in travel behavior modeling. Transportation Research Part A 101, 190-202.

Lin, T., Wang, D., Guan, X., 2017. The built environment, travel attitude, and travel behaviour: Residential self-selection or residential determination? Journal of Transport Geography 65, 111-122.

Næss, P., 2009. Residential self-selection and appropriate control variables in land use: Travel studies. Transport Reviews 29 (3), 293-324.

Næss, P., 2014. Tempest in a teapot: the exaggerated problem of transport-related residential selfselection as a source of error in empirical studies. Journal of Transport and Land Use 7 (3), 57-79.

Saelens, B.E., Sallis, J.F., Lawrence D.F., 2003. Environmental correlates of walking and cycling: Findings from the transportation, urban design, and planning literatures. Annals of Behavioral Medicine 25 (2), 80-91.

Sallis, J.F., Frank, L.D., Saelens, B.E., Kraft, M.K., 2004. Active transportation and physical activity: opportunities for collaboration on transportation and public health research. Transportation Research Part A 38 (4), 249-268.

Scheiner, J., 2006. Housing mobility and travel behaviour: A process-oriented approach to spatial mobility: Evidence from a new research field in Germany. Journal of Transport Geography 14 (4), 287298.

Scheiner, J., Holz-Rau, C., 2013. Changes in travel mode use after residential relocation: a contribution to mobility biographies. Transportation 40 (2), 431-458.

Schwanen, T., Mokhtarian, P.L., 2004. The extent and determinants of dissonance between actual and preferred residential neighborhood type. Environment and Planning B 31 (5), 759-784.

Schwanen, T., Mokhtarian, P.L., 2005. What affects commute mode choice, neighbourhood physical structure or preferences toward neighborhoods? Journal of Transport Geography 13 (1), 83-99.

Tardiff, T.J., 1977. Causal inferences involving transportation attitudes and behavior. Transportation Research 11 (6), 397-404.

Van Acker, V., Mokhtarian, P.L., Witlox, F., 2011. Going soft: on how subjective variables explain modal choices for leisure travel. European Journal of Transport and Infrastructure Research 11 (2), 115-146.

Van Acker, V., Mokhtarian, P.L., Witlox, F., 2014. Car availability explained by the structural relationships between lifestyles, residential location, and underlying residential and travel attitudes. Transport Policy 35, 88-99. 
Van Acker, V., Witlox, F., 2010. Car ownership as a mediating variable in car travel behaviour research using a structural equation modeling approach to identify its dual relationship. Journal of Transport Geography 18 (1), 65-74.

van de Coevering, P., Maat, K., Kroesen, M., van Wee, B., 2016. Causal effects of built environment characteristics on travel behaviour: a longitudinal approach. European Journal of Transport and Infrastructure Research 16 (4), 674-697.

van Wee, B., 2009. Self-Selection: A key to a better understanding of location choices, travel behaviour and transport externalities? Transport Reviews 29 (3), 279-292.

Verplanken, B., Walker, I., Davis, A., Jurasek, M., 2008. Context change and travel mode choice: Combining the habit discontinuity and self-activation hypotheses. Journal of Environmental Psychology 28 (2), 121-127.

Wang, D., Lin, T., 2018. Built environment, travel behavior, and residential self-selection: a study based on panel data from Beijing, China. Transportation DOI: 10.1007/s11116-017-9783-1

Wolday, F., Cao, J., Næss, P., 2018. Examining factors that keep residents with high transit preference away from transit-rich zones and associated behavior outcomes. Journal of Transport Geography 66, 224-234.

Woods, L., Ferguson, N.S., 2014. The influence of urban form on car travel following residential relocation: a current and retrospective study in Scottish urban areas. Journal of Transport and Land Use 7 (1), 95-104.

\section{Appendix}

P-values of one-way ANOVAs with post-hoc multiple comparison analysis using the LSD method (Group 1: Suburban residents relocated from a suburban-style neighbourhood; Group 2: Suburban residents relocated from a more urbanised neighbourhood; Group 3: Urban residents relocated from a less urbanised neighbourhood; Group 4: Urban residents relocated from an urban-style neighbourhood. Group A: Relocated within last 8 months; Group B: Relocated between 9 to 16 months ago; Group C: Moved between 17 and 24 months ago). Bold = significant at $p<0.05$

A. mode frequency according to current and previous neighbourhood (see Figure 4)

\begin{tabular}{lccc|lccc}
\hline Frequent car use & 1. & 2. & 3. & Frequent PT use & 1. & 2. & 3. \\
\hline 1. Group 1 (0.60) & & & & 1. Group 1 (0.13) & & & \\
2. Group 2 (0.50) & $\mathbf{0 . 0 2}$ & & & 2. Group 2 (0.20) & 0.10 & & \\
3. Group 3 (0.33) & $\mathbf{0 . 0 0}$ & $\mathbf{0 . 0 0}$ & & 3. Group 3 (0.33) & $\mathbf{0 . 0 0}$ & $\mathbf{0 . 0 0}$ & \\
4. Group 4 (0.26) & $\mathbf{0 . 0 0}$ & $\mathbf{0 . 0 0}$ & $\mathbf{0 . 0 3}$ & 4. Group 4 (0.32) & $\mathbf{0 . 0 0}$ & $\mathbf{0 . 0 0}$ & 0.95 \\
\hline Frequent cycling & 1. & 2. & 3. & Frequent walking & 1. & 2. & 3. \\
\hline 1. Group 1 (0.34) & & & & 1. Group 1 (0.10) & & & \\
2. Group 2 (0.40) & 0.21 & & & 2. Group 2 (0.09) & 0.78 & & \\
3. Group 3 (0.48) & $\mathbf{0 . 0 0}$ & $\mathbf{0 . 0 4}$ & & 3. Group 3 (0.33) & $\mathbf{0 . 0 0}$ & $\mathbf{0 . 0 0}$ & \\
4. Group 4 (0.55) & $\mathbf{0 . 0 0}$ & $\mathbf{0 . 0 0}$ & $\mathbf{0 . 0 3}$ & 4. Group 4 (0.34) & $\mathbf{0 . 0 0}$ & $\mathbf{0 . 0 0}$ & 0.68 \\
\hline
\end{tabular}


B. travel attitudes according to current and previous neighbourhood (see Table 4)

\begin{tabular}{lccc}
\hline Pro sustainable travel & 1. & 2. & 3. \\
\hline 1. Group 1 (-0.17) & & & \\
2. Group 2 (-0.06) & 0.18 & & \\
3. Group 3 (0.03) & $\mathbf{0 . 0 0}$ & 0.20 & \\
4. Group 4 (0.10) & $\mathbf{0 . 0 0}$ & $\mathbf{0 . 0 3}$ & 0.23 \\
\hline Pro car & 1. & 2. & 3. \\
\hline 1. Group 1 (0.34) & & & \\
2. Group 2 (0.17) & $\mathbf{0 . 0 3}$ & & \\
3. Group 3 (-0.06) & $\mathbf{0 . 0 0}$ & $\mathbf{0 . 0 0}$ & \\
4. Group 4 (-0.23) & $\mathbf{0 . 0 0}$ & $\mathbf{0 . 0 0}$ & $\mathbf{0 . 0 0}$ \\
\hline
\end{tabular}

C. Frequent travel mode use according to current and previous neighbourhood and moment of relocation (see Figure 5)

\begin{tabular}{|c|c|c|c|c|c|}
\hline Car freq. group 1 & 1. & 2. & PT freq. group 1 & 1. & 2. \\
\hline 1. Group A (0.52) & & & 1. Group A (0.19) & & \\
\hline 2. Group B (0.64) & 0.10 & & 2. Group B (0.10) & 0.19 & \\
\hline 3. Group C (0.65) & 0.09 & 0.96 & 3. Group C (0.11) & 0.28 & 0.82 \\
\hline Cycling freq. group 1 & 1. & 2. & Walking freq. group 1 & 1. & 2. \\
\hline 1. Group A (0.41) & & & 1. Group A (0.17) & & \\
\hline 2. Group B (0.30) & 0.20 & & 2. Group B (0.05) & 0.11 & \\
\hline 3. Group C (0.31) & 0.24 & 0.92 & 3. Group C (0.08) & 0.25 & 0.67 \\
\hline Car freq. group 2 & 1. & 2. & Pt freq. group 2 & 1. & 2. \\
\hline 1. Group A (0.43) & & & 1. Group A (0.24) & & \\
\hline 2. Group B (0.51) & 0.33 & & 2. Group B (0.22) & 0.80 & \\
\hline 3. Group C (0.54) & 0.16 & 0.66 & 3. Group C (0.16) & 0.28 & 0.43 \\
\hline Cycling freq. group 2 & 1. & 2. & Walking freq. group 2 & 1. & 2. \\
\hline 1. Group A (0.44) & & & 1. Group A (0.13) & & \\
\hline 2. Group B (0.39) & 0.52 & & 2. Group B (0.09) & 0.59 & \\
\hline 3. Group C (0.37) & 0.33 & 0.77 & 3. Group C (0.07) & 0.43 & 0.79 \\
\hline Car freq. group 3 & 1. & 2. & PT freq. group 3 & 1. & 2. \\
\hline 1. Group A (0.30) & & & 1. Group A (0.37) & & \\
\hline 2. Group B (0.32) & 0.74 & & 2. Group B (0.29) & 0.12 & \\
\hline 3. Group C (0.35) & 0.33 & 0.55 & 3. Group C (0.32) & 0.30 & 0.52 \\
\hline Cycling freq. group 3 & 1. & 2. & Walking freq. group 3 & 1. & 2. \\
\hline 1. Group A (0.52) & & & 1. Group A (0.30) & & \\
\hline 2. Group B (0.43) & 0.13 & & 2. Group B (0.32) & 0.72 & \\
\hline 3. Group C (0.49) & 0.63 & 0.25 & 3. Group C (0.35) & 0.22 & 0.42 \\
\hline Car freq. group 4 & 1. & 2. & PT freq. group 4 & 1. & 2. \\
\hline 1. Group A (0.27) & & & 1. Group A (0.28) & & \\
\hline 2. Group B (0.29) & 0.75 & & 2. Group B (0.32) & 0.44 & \\
\hline 3. Group C (0.22) & 0.46 & 0.27 & 3. Group C (0.35) & 0.18 & 0.59 \\
\hline Cycling freq. group 4 & 1. & 2. & Walking freq. group 4 & 1. & 2. \\
\hline 1. Group A (0.58) & & & 1. Group A (0.36) & & \\
\hline 2. Group B (0.52) & 0.38 & & 2. Group B (0.29) & 0.25 & \\
\hline 3. Group C (0.56) & 0.85 & 0.45 & 3. Group C (0.36) & 0.93 & 0.18 \\
\hline
\end{tabular}


D. Travel attitudes according to current and previous neighbourhood and moment of relocation (see Figure 6)

\begin{tabular}{|c|c|c|c|c|c|}
\hline Pro sust. travel group 1 & 1. & 2. & Pro car group 1 & 1. & 2. \\
\hline 1. Group A (-0.11) & & & 1. Group A (0.14) & & \\
\hline 2. Group B $(-0.14)$ & 0.81 & & 2. Group B (0.38) & 0.07 & \\
\hline 3. Group C (-0.25) & 0.31 & 0.45 & 3. Group C (0.53) & 0.00 & 0.29 \\
\hline Pro sust. travel group 2 & 1. & 2. & Pro car group 2 & 1. & 2. \\
\hline 1. Group A (-0.05) & & & 1. Group A (-0.02) & & \\
\hline 2. Group B (-0.03) & 0.90 & & 2. Group B (0.18) & 0.14 & \\
\hline 3. Group C (-0.09) & 0.78 & 0.69 & 3. Group C (0.32) & 0.01 & 0.31 \\
\hline Pro sust. travel group 3 & 1. & 2. & Pro car group 3 & 1. & 2. \\
\hline 1. Group A (-0.04) & & & 1. Group A (-0.08) & & \\
\hline 2. Group B (0.03) & 0.43 & & 2. Group B $(-0.08)$ & 0.94 & \\
\hline 3. Group C (0.08) & 0.15 & 0.58 & 3. Group C (-0.02) & 0.50 & 0.57 \\
\hline Pro sust. travel group 4 & 1. & 2. & Pro car group 4 & 1. & 2. \\
\hline 1. Group A (0.12) & & & 1. Group A (-0.24) & & \\
\hline 2. Group B (0.04) & 0.44 & & 2. Group B $(-0.19)$ & 0.67 & \\
\hline 3. Group C (0.13) & 0.98 & 0.40 & 3. Group C (-0.25) & 0.95 & 0.60 \\
\hline
\end{tabular}

